\& Medicinal Chemistry Letters

Elsevier Editorial System(tm) for Bioorganic

Manuscript Draft

Manuscript Number: BMCL-D-20-00895

Title: Design and synthesis of 4-Aminoquinoline-isoindoline-dioneisoniazid triads as potential anti-mycobacterials

Article Type: Short Communication

Keywords: 4-aminoquinoline-isoindoline-dione-isoniazid; Antimycobacterial activity; Cytotoxicity; Selectivity index; Molecular docking.

Corresponding Author: Dr. vipan kumar,

Corresponding Author's Institution: Guru Nanak Dev University

First Author: vipan kumar

Order of Authors: vipan kumar; Anu Rani; Matt D Johansen; Françoise Roquet-Banères; Laurent Kremer; Paul Awolade; Oluwakemi Ebenezer; Parvesh Singh; Sumanjit sumanjit

Abstract: A series of 4-aminoquinoline-isoindoline-dione-isoniazid triads were synthesized and assessed for their anti-mycobacterial activities and cytotoxicity. Most of the synthesized compounds exhibited promising activities against the mc26230 strain of M. tuberculosis with MIC in the range of $3.125-12.5 \mathrm{\mu g} / \mathrm{mL}$ and were non-cytotoxic against Vero cells. The conjugates lacking either isoniazid or quinoline core in their structural framework failed to inhibit the growth of M. tuberculosis; thus, further strengthening the proposed design of triads in the present study.

Suggested Reviewers: Arun Sharma

Penn State Cancer Institute, Hershey, United States

aks14@psu.edu

Raghu Raj

Department of Chemistry, DAV College, Amritsar, Punjab, India

raghusharma4@gmail.com

Gaurav Bhargava

Punjab Technical University, Jalandhar, India

gauravorganic@gmail.com

Yogesh Kumar

Department of Chemistry, Durham University, Durham, UK yogesh.kumar@durham.ac.uk

Matthias Dhooghe

Universiteit Gent, Ghent, Belgium

Matthias.dhooghedugent.be

Kelly Chibale

University of Capetown

kelly.chibaleduct.ac.za 



\section{Department of Chemistry \\ Guru Nanak Dev University, India}

Dr. Vipan Kumar, Ph.D

Assistant Professor

Phone: +91-183-2258802 extn. 3320 (0)

$+91-183-2210078(R)$

(Fax): +91-183-2258819-20 (0)

Email: vipan org@yahoo.com

\section{Professor Matthew Disney \\ Editor-in-chief \\ Bioorganic and Medicinal Chemistry Letters}

Dear Professor Disney

Please find attached herewith the manuscript entitled "Design and synthesis of 4Aminoquinoline-isoindoline-dione-isoniazid triads as potential anti-mycobacterials" for publication in Bioorganic and Medicinal Chemistry Letters. The manuscript describes the synthesis of Aminoquinoline-isoindoline-dione-isoniazid triads having isoniazid and quinoline core in their structural framework along with their anti-mycobacterial evaluation against $\mathrm{mc}^{2} 6230$ strain of $M$. tuberculosis and evaluated for cytotoxicity on Vero cells.

Considering its focus, we firmly believe that this manuscript may be of interest for Bioorganic and Medicinal Chemistry Letters readership and hope it meets the quality requirements for publishing in your journal. All authors declare that they have participated in the study and that they have read, commented, and approved the final version of the paper. All authors state that the corresponding authors have full access to all data in the study and have final responsibility for the decision to submit for publication. There is no conflict of interest stated. This work has not been published and is not being considered for publication elsewhere.

Respectfully yours, Vipan Kumar 


\section{Design and synthesis of 4-Aminoquinoline-isoindoline-dione- isoniazid triads as potential anti-mycobacterials}

Anu Rani ${ }^{\mathrm{a}}$, Matt D. Johansen ${ }^{\mathrm{b}}$, Françoise Roquet-Banères ${ }^{\mathrm{b}}$, Laurent Kremer ${ }^{\mathrm{b}, \mathrm{c}}$ Paul Awolade $^{\mathrm{d}}$, Oluwakemi Ebenezer ${ }^{\mathrm{d}}$, Parvesh Singh ${ }^{\mathrm{d}}$, Sumanjit ${ }^{\mathrm{a}}$, Vipan Kumar ${ }^{\text {a }}$

${ }^{a}$ Department of Chemistry, Guru Nanak Dev University, Amritsar-143005, Punjab, India

${ }^{b}$ Institut de Recherche en Infectiologie (IRIM) de Montpellier, CNRS, UMR 9004 Université de Montpellier, France ${ }^{c}$ INSERM, IRIM, 34293 Montpellier, France

${ }^{d}$ School of Chemistry and Physics, University of KwaZulu-Natal, P/Bag X54001, Westville, Durban, South Africa

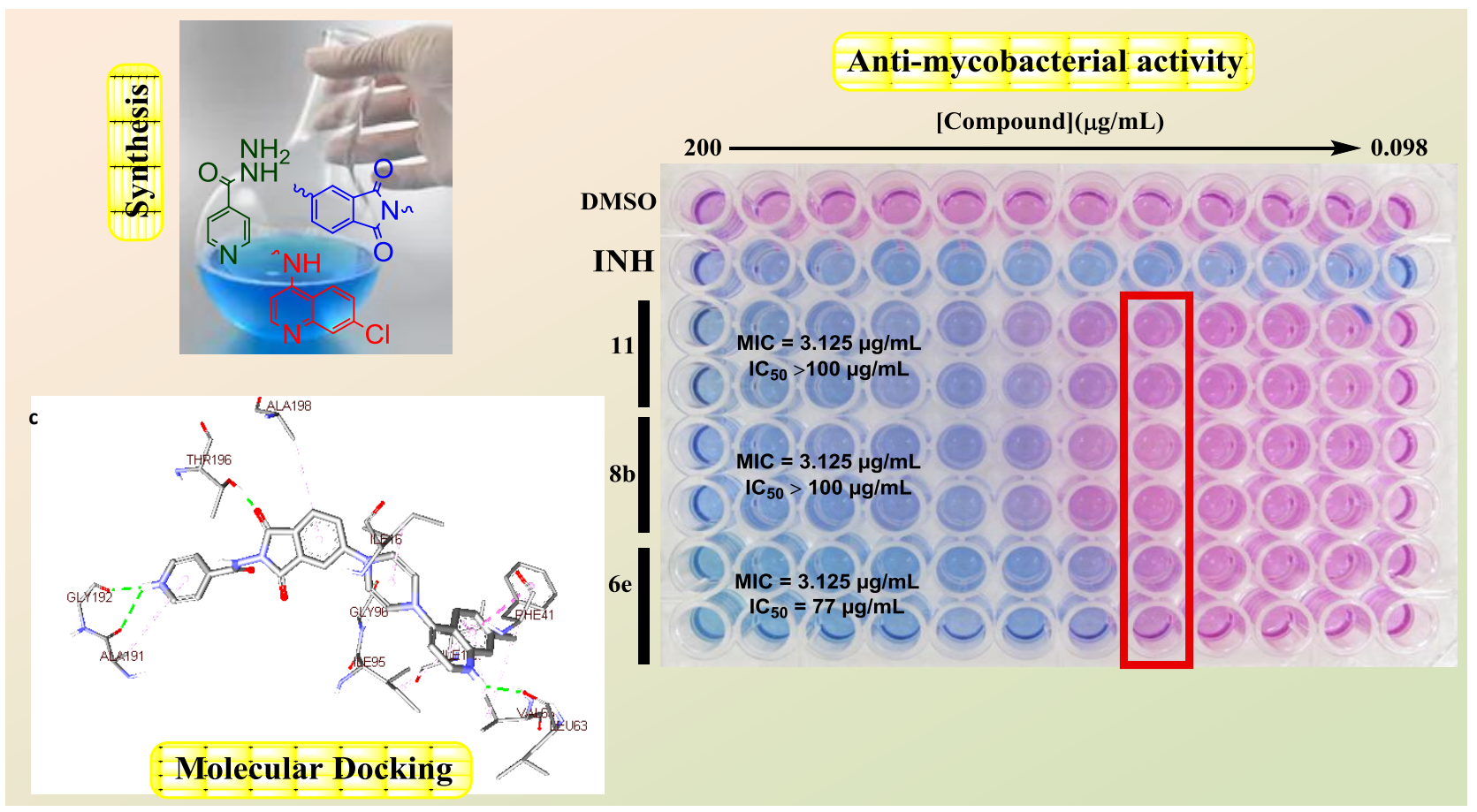


- A series of 4-aminoquinoline-isoindolinedione-isoniazid triads with anti-mycobacterial activities.

- The most active compounds exhibited $\mathrm{MIC}_{99} 3.125 \mu \mathrm{g} / \mathrm{mL}$ against $\mathrm{mc}^{2} 6230$ strain of $M$. tuberculosis.

- Docking studies were performed to delineate the mechanism of action. 


\title{
Design and synthesis of 4-Aminoquinoline-isoindoline-dione- isoniazid triads as potential anti-mycobacterials
}

\author{
Anu Rani ${ }^{a}$, Matt D. Johansen ${ }^{\mathrm{b}}$, Françoise Roquet-Banères ${ }^{\mathrm{b}}$, Laurent Kremer ${ }^{\mathrm{b}, \mathrm{c}}$ Paul \\ Awolade ${ }^{\mathrm{d}}$, Oluwakemi Ebenezer ${ }^{\mathrm{d}}$, Parvesh Singh ${ }^{\mathrm{d}}$, Sumanjit ${ }^{\mathrm{a}}$, Vipan Kumar $*^{\mathrm{a}}$ \\ ${ }^{a}$ Department of Chemistry, Guru Nanak Dev University, Amritsar-143005, Punjab, India \\ ${ }^{b}$ Institut de Recherche en Infectiologie (IRIM) de Montpellier, CNRS, UMR 9004 Université de Montpellier, France \\ ${ }^{c}$ INSERM, IRIM, 34293 Montpellier, France \\ ${ }^{d}$ School of Chemistry and Physics, University of KwaZulu-Natal, P/Bag X54001, Westville, Durban, South Africa \\ *Corresponding Author. Tel: +91 183 2258802-09*3320; Fax: +91 183 2258819-20, Email address: vipan_org@ @yahoo.com
}

\begin{abstract}
A series of 4-aminoquinoline-isoindoline-dione-isoniazid triads were synthesized and assessed for their anti-mycobacterial activities and cytotoxicity. Most of the synthesized compounds exhibited promising activities against the $\mathrm{mc}^{2} 6230$ strain of $M$. tuberculosis with MIC in the range of $3.125-12.5 \mu \mathrm{g} / \mathrm{mL}$ and were non-cytotoxic against Vero cells. The conjugates lacking either isoniazid or quinoline core in their structural framework failed to inhibit the growth of M. tuberculosis; thus, further strengthening the proposed design of triads in the present study.
\end{abstract}

Keywords: 4-aminoquinoline-isoindoline-dione-isoniazid, Anti-mycobacterial activity, Cytotoxicity, Selectivity index, Molecular docking.

\section{Introduction}

Tuberculosis (TB), an infectious disease caused by the bacterium, Mycobacterium tuberculosis, has resulted in chronic granulomatous lesions in the lungs, which can be accompanied by extrapulmonary infection foci in the skin, brain and lymph nodes [1]. The disease is the major cause of death after the Human Immune-deficiency Virus (HIV), accounting for 1945 deaths every day [2]. World Health Organization (WHO) estimated that at least 10 million people developed TB with 1.3 million deaths in 2017 [3]. Despite the availability of an important variety of drugs, TB remains a significant global health threat [4-5]. The foremost obstacle in the total eradication of TB is the development of resistance of $M$. tuberculosis to many existing drugs, which has led to the appearance of multidrug-resistance (MDR) and extensively drug-resistant (XDR) strains [6-11]. Also, TB and HIV co-infection is a major concern with nearly two-thirds 
of the patients diagnosed with TB also being HIV-1 seropositive [12]. The re-designing and repositioning of known anti-TB scaffolds is an effective strategy for the development of new frameworks with favorable pharmacological profiles such as high efficacy and low toxicity [13]. Moreover, this strategy can enable the rapid synthesis of highly effective compounds that are already clinically approved, ultimately shortening the drug commercialization pipeline.

Isoniazid (INH), a first-line anti-TB drug, is the most powerful agent used to treat $M$. tuberculosis infection since 1952 [14]. It is a pro-drug requiring activation via enzyme catalaseperoxidase encoded by $k a t G$ to its active form [15]. The activated metabolite of INH inhibits the synthesis of mycolic acid, a vital component of the mycobacterial cell wall, by targeting the enoyl-ACP reductase InhA of the type II fatty acid synthase [16-18]. The decrease in catalaseperoxidase activity as a result of $k a t G$ mutations is considered as the most common mechanism associated with INH resistance [19]. Among all the genes involved in INH resistance, excluding katG, mutations of InhA confer clinically relevant levels of resistance to INH. Multiple other genes such as nat coding for $N$-acetyltransferase (NAT) contribute to resistance to INH in M. tuberculosis before KatG activation. Furthermore, both NAT and KatG enzymes interact with the pro-drug directly [20]. Following INH metabolism in the liver, hydrazine metabolites (nitrogen-centered free radicals) are produced which generate highly reactive oxygen species and act as a stimulator of lipid peroxidation, resulting in cell death and hepatic necrosis [21-22]. As INH is the major therapeutic arsenal in the treatment of TB infection, continuous efforts are being made to develop new INH derivatives with greater activity, low cytotoxicity, and fewer side effects [23-24]. Several current reports show that the amalgamation of hydrophobic moieties into the basic structure of INH can enhance the penetration of the drug into the lipophilic cell wall of the bacterium [25]. Further, the N-acetyltrans-2 (NAT2) promoted inactivation of INH could also be avoided by functionalizing its hydrazine group [26].

Quinoline moiety is present in a variety of natural products and has diverse biological properties. Notably, quinoline appears as a central core in the recently developed anti-TB drugs such as TMC 207 or bedaquiline and some fluoroquinolones viz. gatifloxacin, and moxifloxacin (Figure 1) [27].

Recently, we introduced a functionalized isoindoline-1,3-diones into the alkyl chain of 4aminoquinolines to access their anti-mycobacterial potency. The compounds were promising 
candidates with a MIC of 5.9-6.25 $\mu \mathrm{g} / \mathrm{mL}$ against the $\mathrm{mc}^{2} 6230$ strain of $M$. tuberculosis (Figure 2) [28-29]. Motivated by these results and in continuation [30], the present work is a logical extension and involves the synthesis and anti-mycobacterial evaluation of 4aminoquinoline-isoniazid hybrids linked via isoindoline-1,3-diones. The length of the alkyl chain spacer between the pharmacophores along with the position of INH and 4aminoquinoline around the isoindoline-1,3-dione were meticulously altered to study their influence on Structure-Activity Relationship.

\section{Results and Discussion}

\subsection{Synthetic Chemistry:}

For the synthesis of first series of desired 4-aminoquinoline-isoindoline-dione-isoniazid triads, 6a-e, the reaction of substituted phthalic anhydride $\mathbf{1}$ with quinoline based diamines $\mathbf{2}$ was carried out in $\mathrm{DMSO}$ at $150{ }^{\circ} \mathrm{C}$ for $5 \mathrm{~min}$, in a microwave synthesizer to result in 4aminoquinoline-isoindoline-diones 5a-e. EDC-HOBt promoted amide coupling between 5a-e and isoniazid afforded the corresponding conjugates 6a-e in moderate to good yields (Scheme 1).

Another set of 4-aminoquinoline-isoindoline-dione-isoniazid triads, 8a-g were prepared via an initial microwave heating of substituted phthalic anhydride $\mathbf{1}$ with isoniazid $\mathbf{3}$ to result in isoniazid-isoindoline-dione 7. Amide/Ester coupling between 7 and quinoline based diamine 2/quinoline based alcohol 2' afforded 8a-g in good yields. A cycloalkyl viz. piperazinyl analogue 11 was also synthesized to determine the influence of alkyl chain on antimycobacterial activities. Further, in order to rationalize the anti-mycobacterial effect of quinoline core in the present series of triads, amide-tethered isoniazid-isoindoline-dione conjugates 13a-b were synthesized via an initial treatment of $\mathbf{1}$ with amino acids $\mathbf{4}$ to afford 12 with subsequent treatment with isoniazid using standard coupling procedure. The structures of the synthesized 4-aminoquinoline-isoindoline-isoniazid conjugates were assigned based on the spectral and analytical evidence. For example, the compound $6 \mathbf{a}$ showed a molecular ion peak at 515.1177 in its high-resolution mass spectrum (HRMS). The significant features of its ${ }^{1} \mathrm{H}$ NMR spectrum involved the presence of a triplet at $\delta 3.82$ because of methylene $\left(\mathrm{N}_{-} \mathrm{CH}_{2}-\right)$; two doublets at $6.62(J=5.3 \mathrm{~Hz})$ and $7.76(J=2.2 \mathrm{~Hz})$ corresponding to quinoline protons along with a multiplet of isoindoline ring protons at 8.27-8.31. The presence of signals in its ${ }^{13} \mathrm{C}$ NMR 
spectrum at $\delta 164.6,164.7,167.7$, and 167.8 corresponding to imide- and amide carbonyls, along with methylene carbons at 36.5 and 40.7 further validated the assigned structure.

\subsection{In vitro anti-mycobacterial and cytotoxic evaluation:}

The synthesized 4-aminoquinoline-isoniazid conjugates were assessed for their antimycobacterial activities against avirulent M. tuberculosis $\mathrm{mc}^{2} 6230$ strain and the results are enlisted in Table 1. The cytotoxicity of all derivatives to mammalian Vero cells was also evaluated to establish whether the observed activities were due to their inherent antimycobacterial ability or due to cytotoxicity (Table 1). As evident, the compounds showed promising anti-mycobacterial activities, although they were not as active as INH. A closer examination of the results showed the activity dependence on both the length of the alkyl chain between the pharmacophores as well as the position of INH and 4-aminoquinoline around isoindoline core. Among the 4-aminoquinoline-isoindoline-1,3-diones 5a-e (without INH-core), the compounds lack any anti-mycobacterial activity except $\mathbf{5 c}$ and $\mathbf{5 d}$ with weak activity but cytotoxicity. Inclusion of INH among these conjugates not only improved their antimycobacterial activity substantially but also decreased their cytotoxicity as seen in triads, 6a-e. The improvement in anti-mycobacterial and cytotoxicity profile is apparent at longer chain lengths, as displayed by $\mathbf{6 d}$ and $\mathbf{6 e}$ with $\mathrm{MIC}_{99}$ of 12.5 and $3.1 \mu \mathrm{g} / \mathrm{mL}$ and $\mathrm{IC}_{50 \mathrm{~s}}$ of 73 and 77 $\mu \mathrm{g} / \mathrm{mL}$, respectively.

Furthermore, interchanging the position of INH with quinoline diamines around isoindoline core in compound 8a-e improved the anti-mycobacterial activities without much dependence on the alkyl chain length. The triad 8e with an octyl spacer not only retained the antimycobacterial efficacy $\left(\mathrm{MIC}_{99}=3.1 \mu \mathrm{g} / \mathrm{mL}\right)$, it is also non-cytotoxic $\left(\mathrm{IC}_{50} \geq 100 \mu \mathrm{g} / \mathrm{mL}\right)$. The inclusion of a cyclic amine viz. piperazine instead of alkyl amine as in triad $\mathbf{1 1}$ also resulted in the good anti-mycobacterial activity.

The conjugates, 13a and 13b without a quinoline core, did not show any substantial antimycobacterial activity; thus, justifying the importance of the proposed design of 4aminoquinoline-isoindoline-dione-isoniazid triads to elicit anti-mycobacterial activity and reduce cytotoxicity.

Relating the activity and cytotoxicity data of currently synthesized compounds $(\mathbf{6 e}, \mathbf{8 e}, \mathbf{1 1})$ with our earlier report (I-IV) [28-31], the introduction of INH at C-5 of isoindoline ring not only 
improved anti-mycobacterial activity but also resulted in the reduction of cytotoxicity (Figure 2). The general anti-TB SAR/cytotoxicity of the synthesized series of 4-aminoquinolineisoindoline-isoniazid triads is elucidated in Figure 3.

\subsection{Molecular docking studies and ADME properties prediction}

Molecular docking studies were conducted using AutoDock to explore the potential binding interactions of selected compounds with $M$. tuberculosis enoyl-acyl carrier protein reductase (InhA; PDB ID: 4TZK). InhA is a prominent enzyme involved in the biosynthesis of mycolic acid for mycobacterial cell wall and the molecular target of isoniazid. Six inhibitors were docked into the active site of InhA, as shown in Figures $\mathbf{4}$ and 5, while the docking results are summarized in Table 2.

In consonant with the experimental results, the binding energies and receptor interactions of compounds 6e, 8e and 11 were superior to compounds I, II and III (Table 2). For instance, in compound I (Figure 4a), the chlorine atom was sandwiched between residues Phe149 and Met199 via hydrophobic interactions while the amino group of quinoline core formed a hydrogen bond interaction with the hydroxyl oxygen of Gly192. The isoindoline core also afforded alkyl, $\pi-\pi$ stacking, $\pi$-alkyl, and $\pi-\sigma$ interactions with Ile95, Phe41, Val65, Ile122, Phe149, and Met199. A similar binding profile was observed for the isoindoline core of compound II (Figure 2), i.e. $\pi$ - $\pi$ stacking with residue Phe41 as well as $\pi$ - $\sigma, \pi$-alkyl, and alkyl interactions with Ile21, Val65, Ile122, Phe149, Ala198, Met147 and Ile95. The unit also featured a hydrogen bond interaction between the isoindoline and Ile95, while the fluorine substituent formed a halogen bond with Asp64. The docked complex of III (Figure 3) was established in the hydrophobic pocket created by hydrophobic interaction with the side chains of ten amino acid residues. Surprisingly, the oxygen atom of the isoindoline core formed a strong hydrogen bond with Tyr168. The interaction was absent in compounds I and II; hence, a potential platform for further structural modifications to enhance the anti-mycobacterial activity.

Furthermore, compound $\mathbf{6 e}, \mathbf{8 e}$ and $\mathbf{1 1}$ binds in essentially the same manner within the active site of InhA. The compound 6e-InhA complex is characterized by six hydrogen bond interactions between the amino acid residues of side chain and both the oxygen atom of isoniazid moiety and the amine linker. Besides, the quinoline core was anchored in the 
hydrophobic pocket containing Val65, Ile95, Phe41, and Ile122, which suggested that the twofold increase in potency might stem from additional interactions between the isoniazid moiety and the side chains of the active site residues. Furthermore, the isoniazid moiety in compound 8e interacts with Gly192, Ala191 and Lys165 via hydrophobic and H-bonding interactions while the aminoquinoline group formed hydrophobic interactions with residue Val65, Leu63, Gly14 and Gly40, respectively. Other residues that made H-bond interactions include, Gly96, Ile95, Ile165, which also serve as motivators for the stabilization of the inhibitor within the catalytic pocket of the receptor. Moreover, the docked complex of compound 11 showed additional hydrogen bond interactions between the piperazine ring and the carbonyl oxygen of Gly96, which was accompanied by hydrophobic interaction with Ile16.

On the other hand, the molecular descriptors ADME properties were calculated for potent compounds using web-based software pkCSM (http://biosig.unimelb.edu.au/pkcsm/prediction) and SwissADME (http://www.swissadme.ch/). The results are presented in Table 2. The drug candidates with TPSA values of $140 \AA$ or lower are expected to have good absorption. Accordingly, all the compounds were within this limit, i.e., $<140 \AA$, which implies that these compounds fulfilled the optimal requirement for drug absorption.

\section{Conclusion}

In conclusion, a series of 4-aminoquinoline-isoindoline-dione-isoniazid triads have been synthesized with the target of reviewing their SAR against $M$. tuberculosis. Nearly all of the synthesized conjugates presented promising anti-TB activity and useful selectivity index. The conjugates without the quinoline core 13a/13b and the INH nucleus 5a-e failed to inhibit the growth of M. tuberculosis as was observed in our previous report on 1,8-naphthalimideisoniazid hybrids [31], further validating the design of triads in the present case.

Electronic Supplementary Information: Material and methods, Synthesis and spectral data of

all the compounds along with scanned ${ }^{1} \mathrm{H}$ and ${ }^{13} \mathrm{C}$ NMR spectra of few representative compounds viz. 5a, 6a, $\mathbf{6 b}, \mathbf{7}, \mathbf{8 a}, \mathbf{9}, \mathbf{1 3 a}$ and $\mathbf{1 1}$ are provided in the electronic supplementary information.

Acknowledgments: The authors thank the Council of Scientific and Industrial Research, New Delhi, India for funding (AR Ref. No. 09/254(0269)/2017-EMR-I). MDJ received a postdoctoral fellowship from Labex EpiGenMed under the program « Investissements d'avenir 
»(ANR-10-LABX-12-01). LK acknowledges the support by the Fondation pour la Recherche Médicale (FRM) (DEQ20150331719). PS acknowledges to the National Research Foundation (NRF), South Africa for a Competitive Grant for unrated Researchers (Grant No. 121276), and the Centre for High-Performance Computing (CHPC), Cape Town, for the supercomputing facilities.

\section{Conflict of interest}

The authors have declared no conflict of interest.

\section{References:}

1. (a) World Health Organization, Annual Report, 2017. http://apps.who.int/iris/ bitstream/10665/254762/1/978929022584-eng. pdf (b) K. F. M. Pasqualoto, E. I. Ferreira, O. A. Santos-Filho, A. J. Hopfinger, J. Med. Chem. 47 (2004) 3755. (c) P. Modi, S. Patel, M. Chhabria, Bioorg. Chem. 87 (2019) 240.

2. "Get the Facts about TB Disease" TBFACTS.ORG, http://www.tbfacts.org/ symptomstb.

3. World Health Organization (WHO). Global tuberculosis report. 2019. Available from: https://www.who.int/tb/publications/global_report/tb19_Exec_Sum_12Nov2019.pdf?ua=1

4. D. S. Reddy, M. Kongot, S. P. Netalkar, M. M. Kurjogi, R. Kumar, F. Avecilla, A. Kumar, Eur. J. Med. Chem. 150 (2018) 864.

5. A. Zumla, P. Nahid, S. T. Cole, Nat. Rev. Drug Discov. 12 (2013) 388.

6. T. Cohen, M. C. Becerra, M. B. Murray, Microb. Drug Resist. 10 (2004) 280.

7. J. Chen, S. Zhang, P. Cui, W. Shi, W. Zhang, Y. Zhang, J. Antimicrob. Chemother. 72 (2017) 3272 .

8. A. V. Deun, A. K. Maug, V. Bola, R. Lebeke, M. A. Hossain, W. B. de Rijk, L. Rigouts, A. Gumusboga, G. Torrea, B. C. de Jong, J. Clin. Microbiol. 51 (2013) 2633.

9. R. E. Stanley, G. Blaha, R. L. Grodzicki, M. D. Strickler, T. A. Steitz, Nat. Struct. Mol. Biol. 17 (2010) 289.

10. C. Vilcheze, W. R. Jacobs, Microbiol. Spectr. 2 (2014) 0014.

11. X. Lu, J. Tang, S. Cui, B. Wan, S. G. Franzblauc, T. Zhang, X. Zhang, K. Ding, Eur. J. Med. Chem., 125 (2017) 41.

12. W. Manosuthi, S. Wiboonchutikul, S. Sungkanuparph, AIDS Res. Ther. 13 (2016) 22. 
13. K. Anil, A. Eric, L. Nacer, G. Jerome, A. Koen, Nature 469 (2011) 483.

14. V. H. Teixeira, C. Ventura, R. Leitão, C. Ràfols, E. Bosch, F. Martins, et al., Mol. Pharm. 12 (2015) 898.

15. E. H. Robitzek, I. Selikoff. J. Am Rev Tuberc 65 (1952) 402.

16. A. Banerjee, E. Dubnau, A. Quemard, V. Balasubramanian, K. S. Um, T. Wilson, et al. Science 263 (1994) 227.

17. H. Marrakchi, G. Laneelle, A. Quemard. Microbiology 146 (2000) 289.

18. C. Vilchèze, F. Wang, M. Arai, M. H. Hazbón, R. Colangeli, L. Kremer, T. R. Weisbrod, D. Alland, J. C. Sacchettini, W. R. Jacobs Jr, Nat. Med. 12 (2006) 1027-1029.

19. Y. Zhang, B. Heym, B. Allen, D. Young, S. Cole, Nature 358 (1992) 591.

20. A. U. Nusrath, G. P. Doss C, T. Kumar, S. Swathi, A. R. Lakshmi, L. E. Hanna, J. Global Antimicrobial Resistance 11 (2017) 57.

21. E. Vavríkova, S. Polanc, M. Kocevar, K. Horvati, S. Bosze, J. Stolaríkova, K. Vavrova, J. Vinsova, Eur. J. Med. Chem. 46 (2011) 4937.

22. E. Vavríkova, S. Polanc, M. Kocevar, J. Kosmrlj, K. Horvati, S. Bosze, J. Stolaríkova, A. Imramovský, J. Vinsova, Eur. J. Med. Chem. 46 (2011) 5902.

23. K. Elumalai, M. A. Ali, M. Elumalai, K. Eluri, S. Srinivasan, J. Acute Disease. 2 (2013) 316.

24. L. Matei, C. Bleotu, I. Baciu, C. Draghici, P. Ionita, A. Paun, M.C. Chifiriuc,A. Sbarcea, I. Zarafu, Bioorg. Med. Chem. 21 (2013) 5355.

25. (a) J. Sandy, A. Mushtaq, A. Kawamura, J. Sinclair, E. Sim, M. Noble, J. Mol. Biol. 318 (2002) 1071-1083. (b) Yuan-Qiang Hu, S. Zhang, F. Zhao, C. Gao, Lian-Shun Feng, ZaoSheng Lv, Z. Xu, X. Wu. Eur. J. Med. Chem. 133 (2017) 255.

26. D. Shingnapurkar, P. Dandawate, C. E. Anson, A. K. Powell, Z. Afrasiabi, E. Sinn, S. Pandit, S. K. Venkateswara, S. Franzblau, S. Padhye, Bioorg. Med. Chem. Lett. 22 (2012) 3172.

27. (a) J. C. Sundaramurthi, L. E. Hanna, S. Selvaraju, S. Brindha, J. Joel Gnanadoss, S. Vincent, H. Singh, S. Swaminathan, Tuberculosis 100 (2016) 69. (b) B. Villemagne, C. Crauste, M. Flipo, Eur. J. Med. Chem. 51 (2012) 1. (c) D. T. Hoagland, J. Liu, R. B. Lee, R. 
E. Lee, Adv. Drug Deliv. Rev. 102 (2016) 55. (d) G. Kumar, A. Sathe, V. S. Krishn, D. Sriram, S. M. Jachak, Eur. J. Med. Chem.157 (2018) 1-13. (e) A. H. Diacon, A. Pym, M.

Grobusch, R. Patientia, R. Rustomjee, L. Page-Shipp, C. Pistorius, R. Krause, M. Bogoshi, G. Churchyard, A. Venter, J. Allen, J. C. Palomino, T. De Marez, R. N. Veziris, M. Ibrahim, N. Lounis, T. Andries, V. Jarlier, PLoS ONE, 6 (2011) 17556. (f) J. Cohen, Science, 2013, $339,130$.

28. A. Rani, A. Viljoen, Sumanjit, L. Kremer, V. Kumar, ChemistrySelect, 2 (2017) 10782.

29. A. Rani, A. Viljoen, M. D. Johansen, L. Kremer, V. Kumar. RSC Adv. 9 (2019) 8515.

30. (a) Shalini, A. Viljoen, L. Kremer, V. Kumar, Bioorg. Med. Chem. Lett. 28 (2018) 1309. (b) Shalini, M. D. Johansen, L. Kremer, V. Kumar, Bioorg. Chem. 92 (2019) 103241. (c) A Singh, A Viljoen, L Kremer, V Kumar, ChemistrySelect 3 (29), 8511.

31. Shalini, M. D. Johansen, L. Kremer, V. Kumar, Chem. Bio. Drug Design 94 (2019) 1300 .

\section{Captions:}

Figure 1: Chemical structures of standard drug isoniazid (INH) and quinoline based anti-tubercular agents.

Figure 2: Comparison of activity against $\mathrm{mc}^{2} 6230$ and cytotoxicity against Vero cells of $\mathbf{6 e}, \mathbf{8 e}$ and $\mathbf{1 1}$ with previously reported scaffolds I, II and III.

Scheme 1: Synthesis of 4-aminoquinoline-isoindoline-dione-INH conjugates (6a-e), (8a-e), 11 and (13ab).

Table 1: In vitro anti-mycobacterial activity of synthesized compounds against $M$. tuberculosis mc ${ }^{2} 6230$ and cytotoxicity evaluation on mammalian Vero cells and their selectivity index (SI).

Figure 3: Structure-Activity Relationship (SAR) of both series of synthesized 4-aminoquinolineisoindoline-dione-INH triads.

Figure 4: Binding interactions of compounds (a) I (b) II (c) III

Figure 5: Binding interactions of compounds (a) $6 e$ (b) 8 e (c) 11

Table 2: Molecular descriptors and the binding energy of the potent compounds 


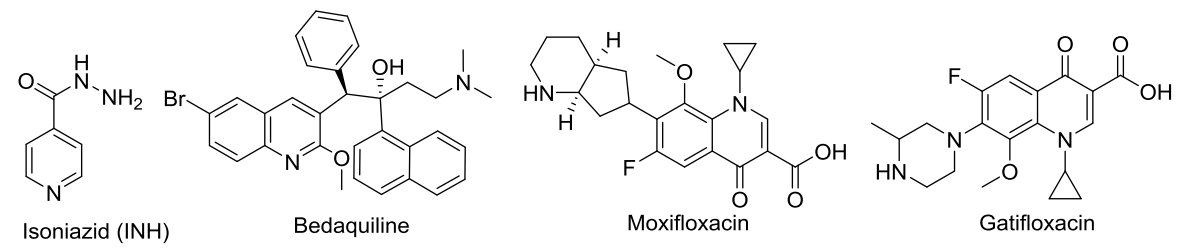

Figure 1: Chemical structures of standard drug isoniazid (INH) and quinoline based antitubercular agents.

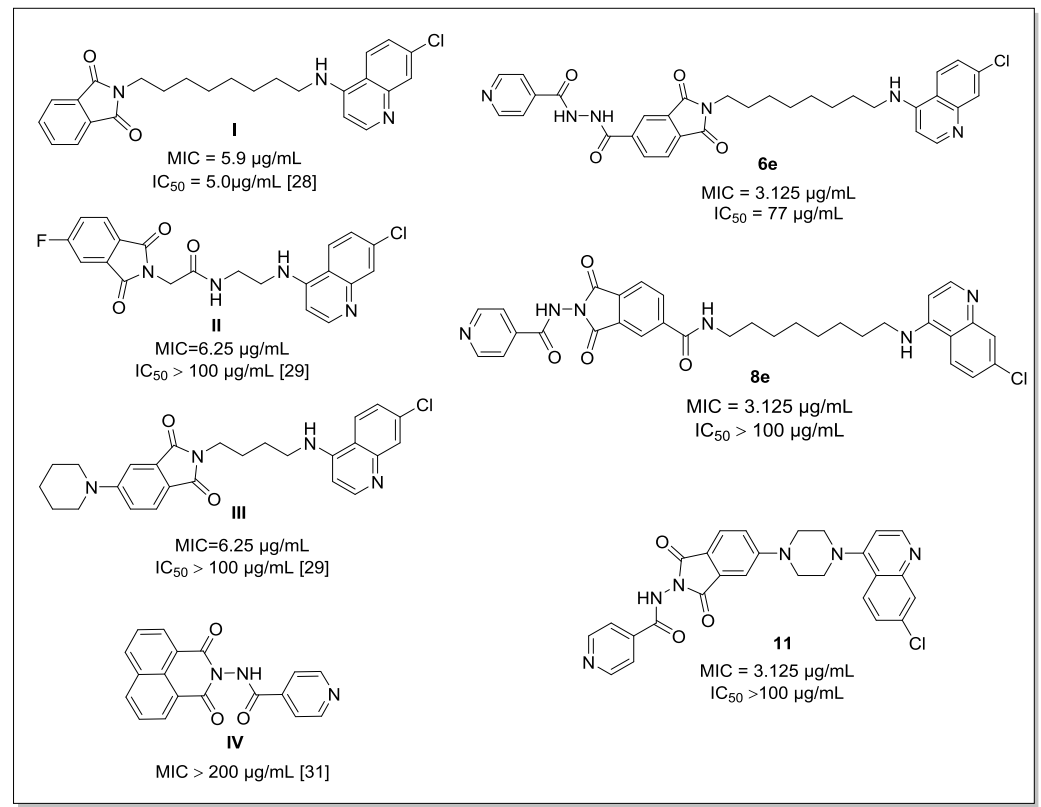

Figure 2: Comparison of activity against $\mathrm{mc}^{2} 6230$ and cytotoxicity against Vero cells of $\mathbf{6 e}, \mathbf{8 e}$ and 11 with previously reported scaffolds I-IV [28-29, 31] 


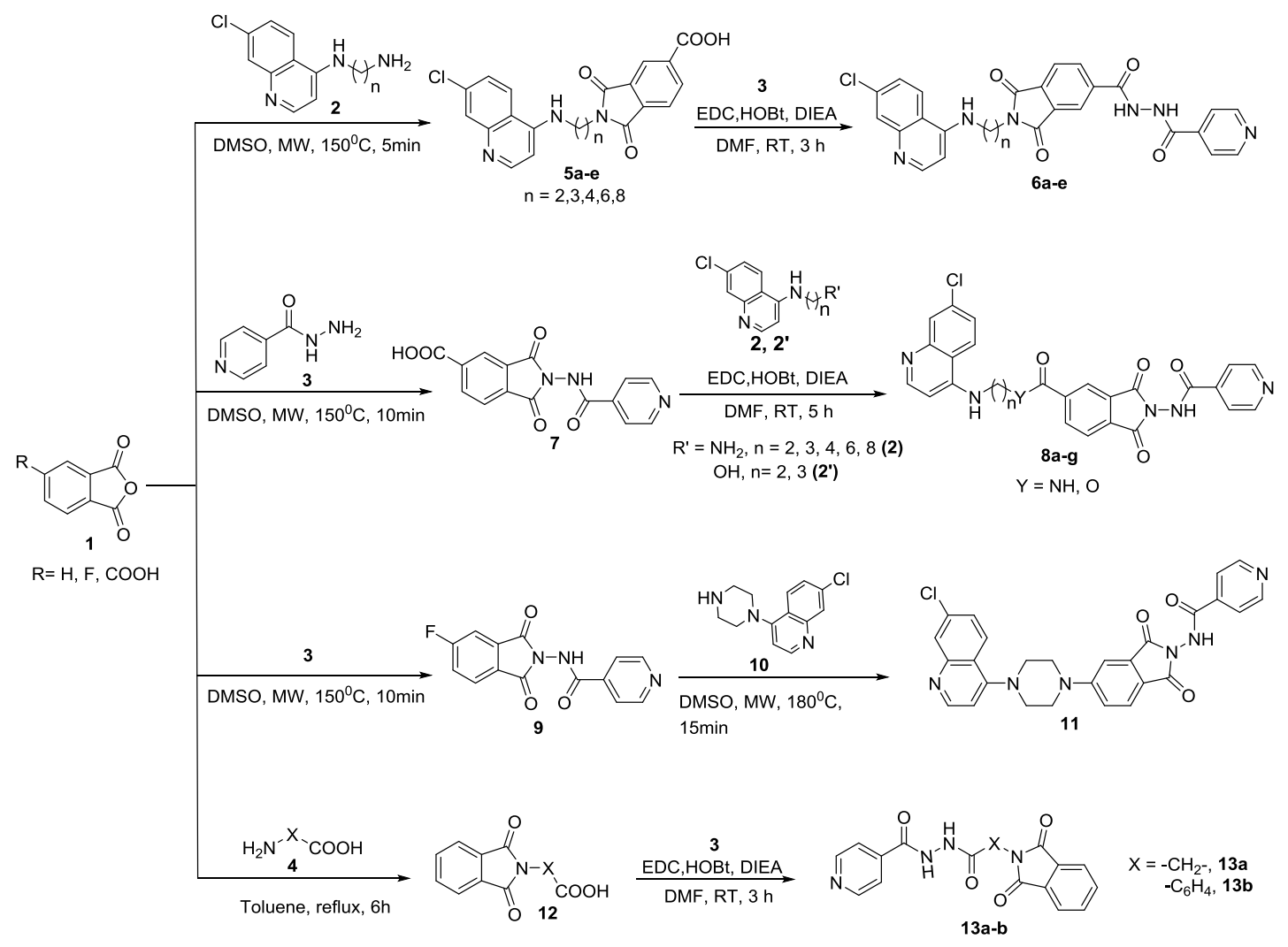

Scheme 1: Synthesis of 4-aminoquinoline-isoindoline-dione-isoniazid conjugates.

Table 1: In vitro anti-mycobacterial activity $\left(\mathrm{MIC}_{99}\right)$ of synthesized compounds against $\mathrm{mc}^{2} 6230$ strain of $M$. tuberculosis and cytotoxicity $\left(\mathrm{IC}_{50}\right)$ evaluation on mammalian Vero cells and their selectivity index (SI).

\begin{tabular}{|c|c|c|c|c|c|}
\hline Code & Structure & $\begin{array}{c}\% \\
\text { Yield }\end{array}$ & $\begin{array}{c}\text { MIC }_{99} \\
(\mu \mathrm{g} / \mathrm{mL})\end{array}$ & $\begin{array}{c}\mathrm{IC}_{50} \\
(\mu \mathrm{g} / \mathrm{mL})\end{array}$ & SI value \\
\hline $5 a$ & & 81 & $>200$ & $>100$ & $>0.5$ \\
\hline $5 b$ & & 76 & 200 & 99 & 0.5 \\
\hline $5 c$ & & 77 & 100 & 17 & 0.2 \\
\hline $5 d$ & & 76 & 100 & 11 & 0.1 \\
\hline
\end{tabular}


5 e

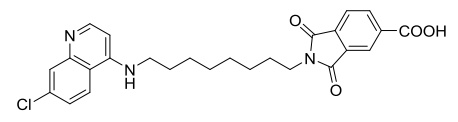

$6 a$

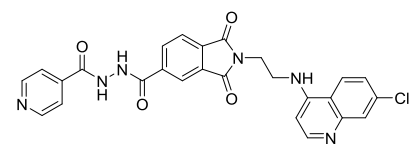

6b

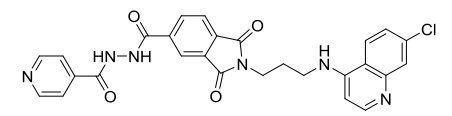

6c

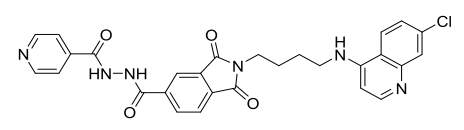

6d

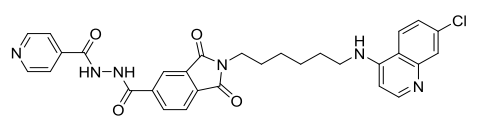

$6 e$

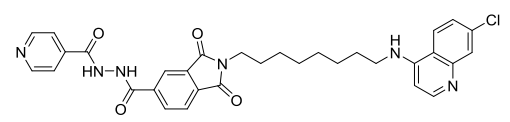

$8 a$

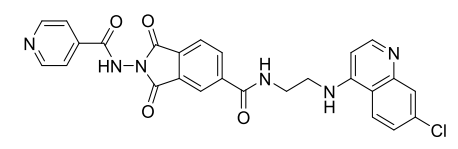

$8 b$

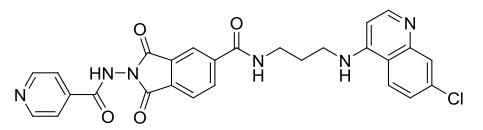

8c

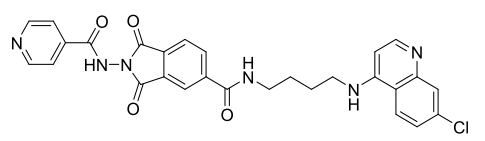

8d

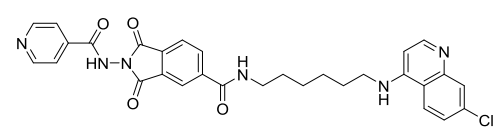

$8 e$

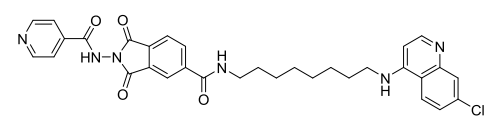

$8 f$

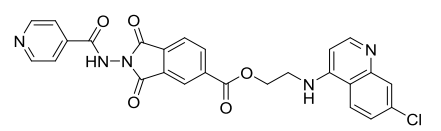

$8 g$

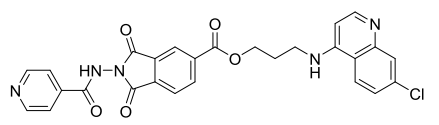

11

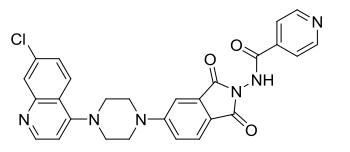

79

200

$>100$

$>0.5$

81

200

$>100$

$>0.5$

76

25

63

2.5

82

12.5

9

0.7

78

12.5

73

5.8

79

3.1

77

79

3.1

33

10.6

77

3.1

85

27

74

12.5

8

0.6

76

6.3

19

3

72

3.1

$>100$

$>31$

85

$>200$

$>100$

$>0.5$

84

6.3

$>100$

$>16$

83

$3.1>100$

$>31$ 
$13 \mathbf{a}$

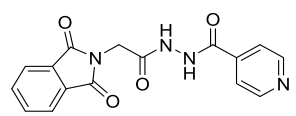

13b

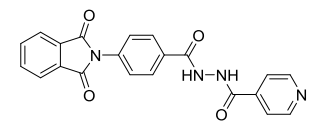

INH

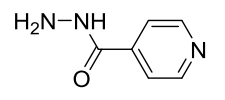

83

85

50

$>100$

$>2$

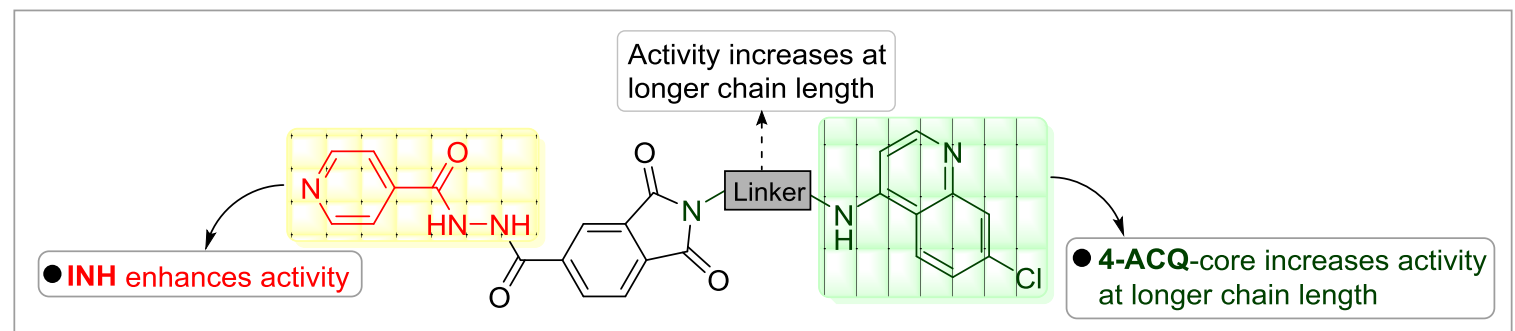

4-ACQ enhanced activity independent of chain length

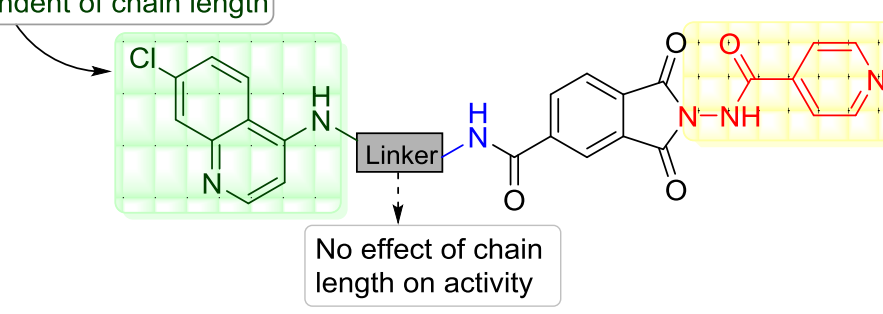

- INH increases activity and reduces cytotoxicity

$\mathrm{NH}=$ Isoniazid

4-ACQ=4-Aminoquinoline

Figure 3: Structure-Activity Relationship (SAR) of both series of synthesized 4aminoquinoline-isoindoline-dione-INH triads. 

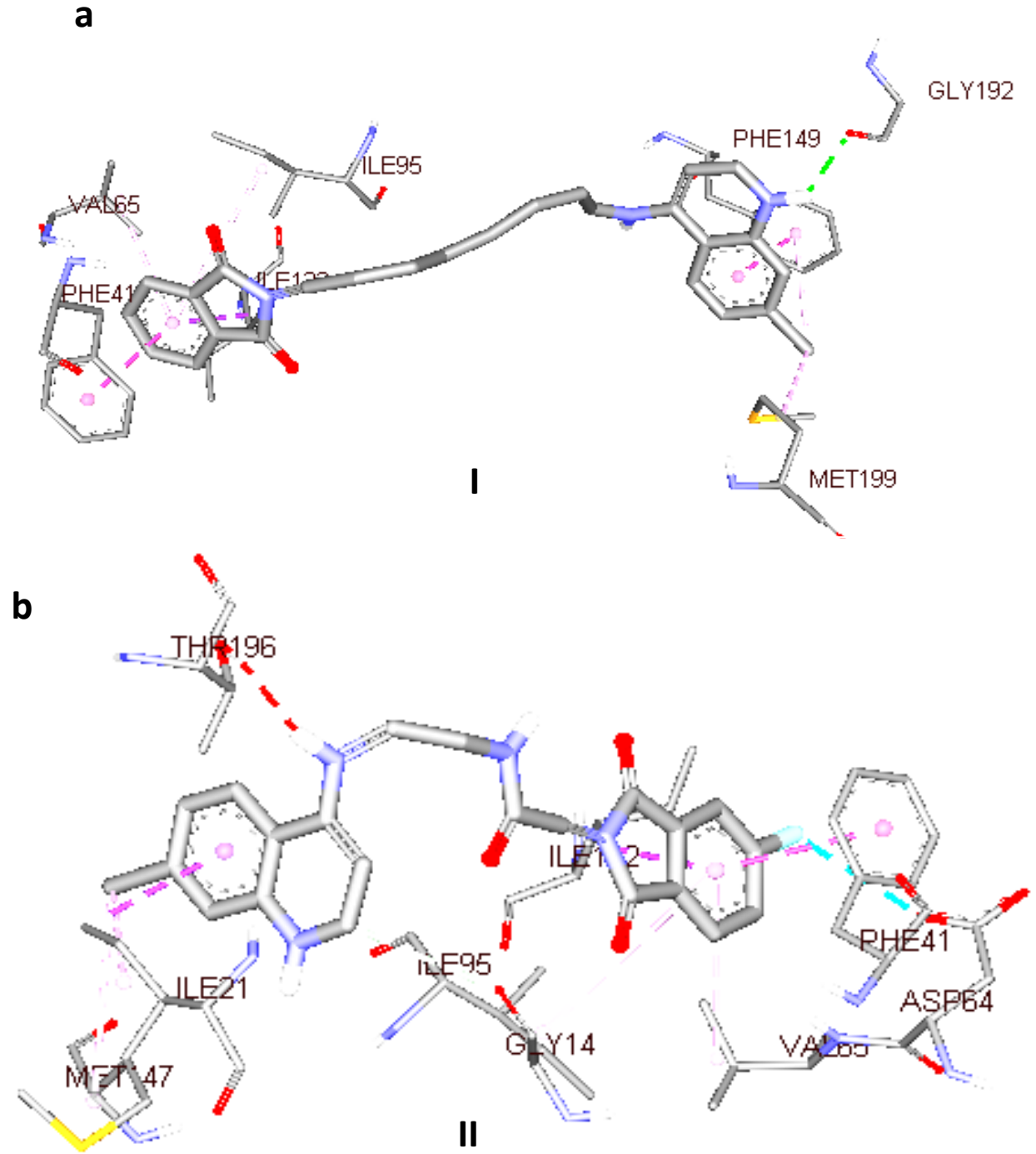

C

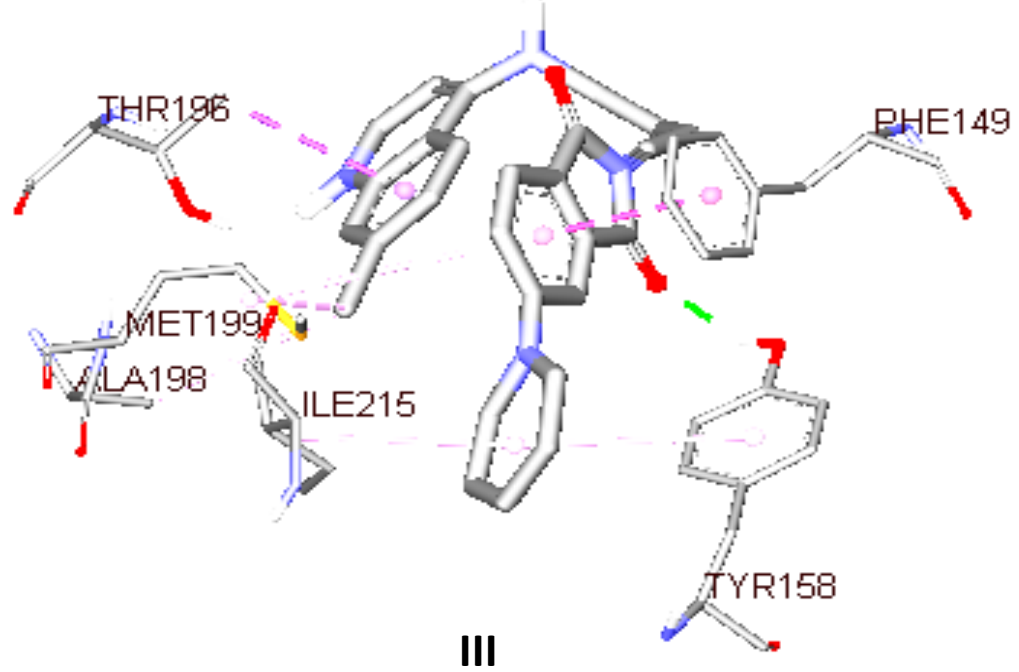

Figure 4: Binding interactions of compounds (a) I (b) II (c) III 
a

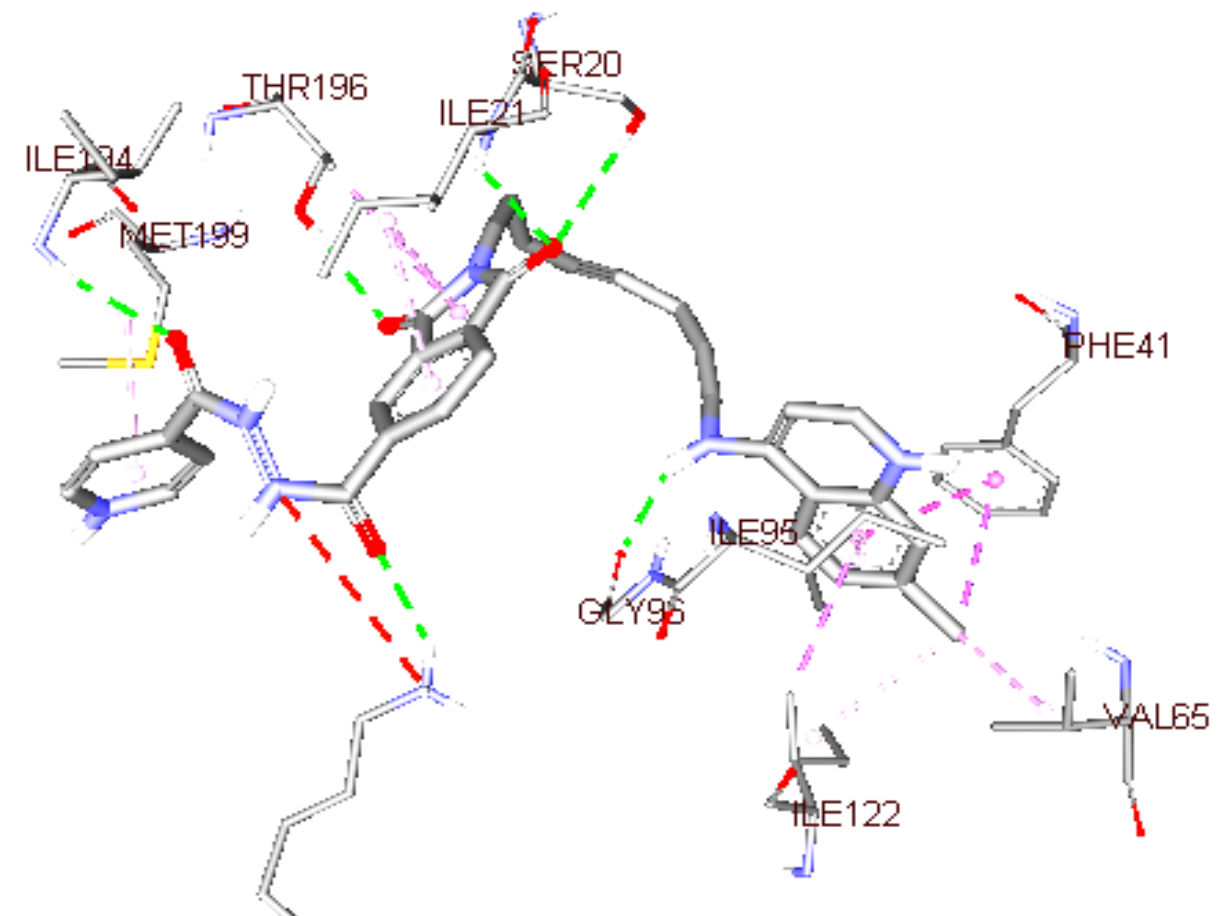

$L / \$ 165 \quad 6 e$

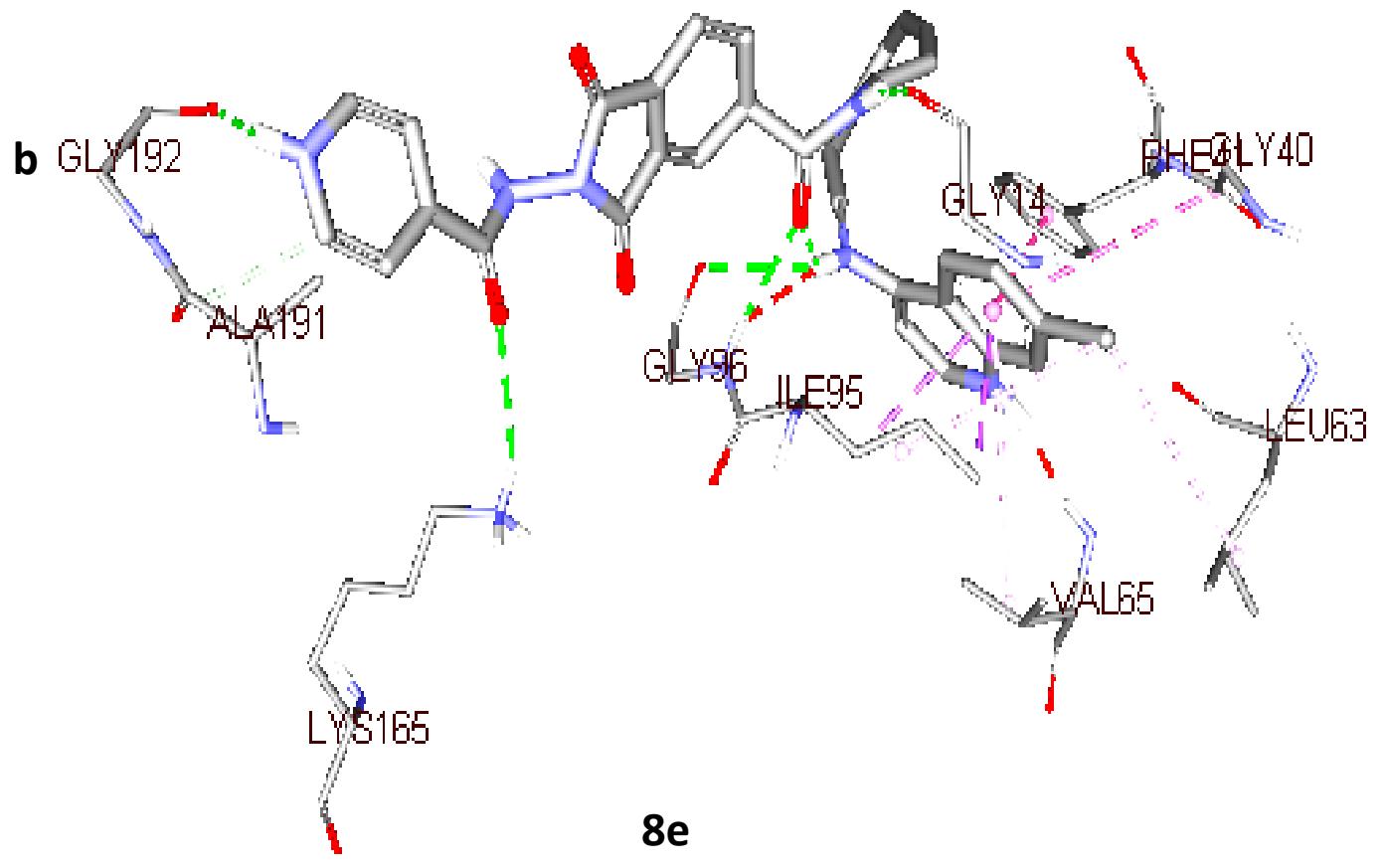




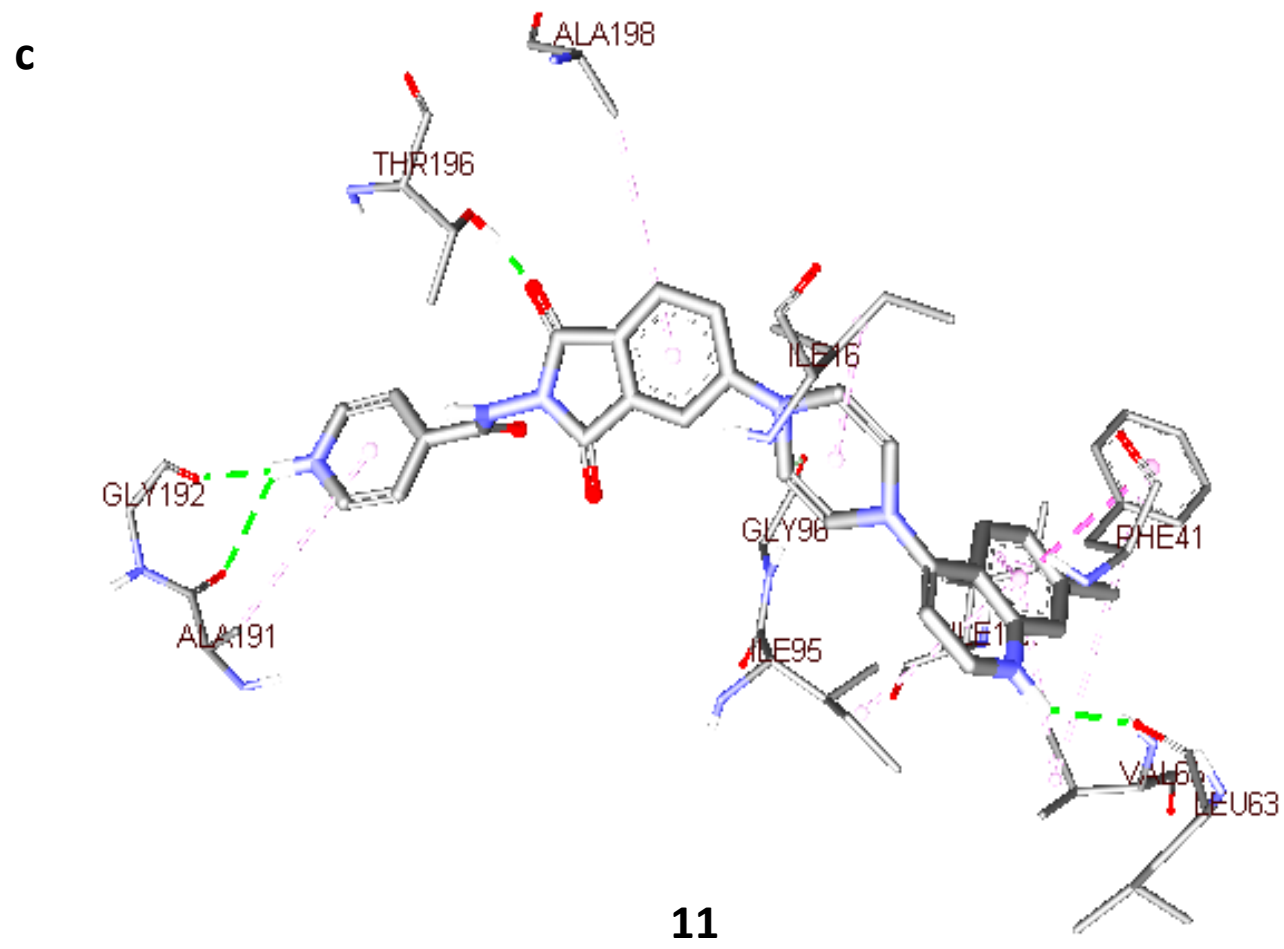

Figure 5: Binding interactions of compounds (a) 6e (b) $8 \mathbf{e}$ (c) 11

Table 2: Molecular descriptors and the binding energy of the potent compounds

\begin{tabular}{llllllllll}
\hline Compound & $\begin{array}{c}\text { B.E } \\
(\mathbf{k c a l} / \mathbf{m o l})\end{array}$ & TPSA & $\log P$ & HBD & HBA & $\log S$ & Caco2 & $\log \boldsymbol{K p}$ & $\log B \boldsymbol{B}$ \\
\hline I & -9.7 & 62.30 & 5.05 & 1 & 3 & -5.5 & 0.465 & -2.773 & 0.133 \\
II & -9.9 & 91.40 & 2.77 & 2 & 5 & -3.716 & 0.645 & -2.816 & -1.407 \\
III & -10.2 & 65.54 & 4.35 & 3 & 3 & -4.945 & 0.76 & -2.877 & 0.231 \\
$\mathbf{6 e}$ & -10.4 & 133.39 & 4.42 & 3 & 6 & -4.094 & 0.768 & -2.735 & -1.745 \\
$\mathbf{8 e}$ & -10.3 & 133.39 & 4.40 & 3 & 6 & -4.324 & 1.65 & -2.735 & -1.544 \\
$\mathbf{1 1}$ & -11.7 & 98.74 & 2.27 & 1 & 5 & -4.044 & 0.692 & -2.767 & -1.129 \\
\hline
\end{tabular}

TPSA - Topological Polar Surface Area $(60$ - 140); log BB - logarithm of predicted blood/brain barrier partition coefficient (-3.0-1.2); Caco-2 - cell membrane permeability (>0.9 is high); HBA - number of hydrogen bond acceptors; HBD number of hydrogen bond donors; $\log K_{\mathrm{p}}$ - predicted skin permeability(SP) $>-2.5$ is low. 


\section{Design and synthesis of 4-Aminoquinoline-isoindoline-dione- isoniazid triads as potential anti-mycobacterials}

Anu Rani ${ }^{a}$, Matt D. Johansen ${ }^{b}$, Françoise Roquet-Banères ${ }^{b}$, Laurent Kremer ${ }^{\text {b,c }}$ Paul Awolade $^{\mathrm{d}}$, Oluwakemi Ebenezer ${ }^{\mathrm{d}}$, Parvesh Singh ${ }^{\mathrm{d}}$, Sumanjit ${ }^{\mathrm{a}}$, Vipan Kumar ${ }^{\mathrm{a}}$

${ }^{a}$ Department of Chemistry, Guru Nanak Dev University, Amritsar-143005, Punjab, India

${ }^{b}$ Institut de Recherche en Infectiologie (IRIM) de Montpellier, CNRS, UMR 9004 Université de Montpellier, France ${ }^{c}$ INSERM, IRIM, 34293 Montpellier, France

${ }^{d}$ School of Chemistry and Physics, University of KwaZulu-Natal, P/Bag X54001, Westville, Durban, South Africa

*Corresponding Author. Tel: +91 183 2258802-09*3320; Fax: +91 183 2258819-20, Email address: vipan_org@yahoo.com

\section{Contents}

1. Experimental section

2. Physical and spectral data of 5a-e, 6a-e, 8a-g, 11 and 13a-b

3. Copies of ${ }^{1} \mathrm{H}$ and ${ }^{13} \mathrm{C}$ NMR spectra of 5a, 6a, 6b, 7, 8a, 9, 13a and 11

\section{Experimental section}

\section{General}

All starting materials and reagents were purchased from Sigma-Aldrich and Merck. Thinlayer chromatography was performed on a film of silica gel that contained a fluorescent indicator $\mathrm{F}_{254}$ supported on an aluminum sheet (Merck). Melting points were determined by open capillary using a Stuart Digital Melting Point apparatus (SMP10) and are uncorrected. ${ }^{1} \mathrm{H}$ NMR spectra were recorded in DMSO-d $\mathrm{d}_{6}$ Jeol 400 (400 MHz) spectrometers while TMS is used as the internal standard. Microwave reactions were performed in an Anton Paar Monowave Initiator+ instrument using a sealed $10 \mathrm{~mL}$ process vials. Reaction times refer to irradiation time at the target temperature, not the total irradiation time. The temperature was measured with an IR sensor. Chemical shift values are specified as parts per million (ppm) downfield from TMS while coupling constant $(J)$ values are in Hertz. Patterns of Splitting are designated as s: singlet, d: doublet, t: triplet, dd: double doublet, m: multiplet, ddd: doublet of doublet of doublet, and br: broad peak. ${ }^{13} \mathrm{C}$ NMR spectra were recorded on Jeol $100 \mathrm{MHz}$ spectrometers in DMSO- $\mathrm{d}_{6}$. High-Resolution Mass Spectra (HRMS) were recorded on a Bruker-micrOTOF-Q II spectrometer using ESI as the ion source. 


\section{General Procedure for the synthesis of 4-aminoquinoline-isoindoline-isoniazid triad:}

Synthesis of 2-(((7-chloroquinolin-4-yl)amino)alkyl)-1,3-dioxoisoindoline-5-carboxylic acid (5a-e):

An equimolar mixture of phthalic anhydride 1 (1 eq.) and 7-chloro-4-aminoquinolinediamines 2 (1 eq.) was dissolved in a $2 \mathrm{~mL}$ of DMSO in a microwave glass vial. The reaction vial was irradiated to $150{ }^{\circ} \mathrm{C}$ for $5 \mathrm{~min}$ in microwave synthesizer. After completion of the reaction as evident from TLC, the vessel contents were poured in water $(20 \mathrm{~mL})$ and solid precipitates obtained were filtered and washed with cold water and recrystallized using absolute ethanol.

Synthesis of 2-(((7-chloroquinolin-4-yl)amino $)$ alkyl)-N'-isonicotinoyl-1,3-dioxoisoindoline-5carbohydrazide (6a-e):

1.0 equivalent of 4-aminoquinoline-isoindoline acids 5, $\mathrm{N}$-ethyl- $\mathrm{N}$-dimethylaminopropyl carbodiimide (EDC) (1.1 eq.), hydroxybenzotriazole $(\mathrm{HOBt}) \quad(1.2$ eq. $)$ and 4diisopropylethylamine (DIPEA) (2 eq.) were mixed in minimum DMF, and the obtained mixture was stirred for $5 \mathrm{~min}$. Isoniazid (1.1 eq.) was subsequently added to the reaction mixture, and the stirring was continued for $3 \mathrm{~h}$ at room temperature. The progress was monitored by thin-layer chromatography (TLC). DMF was then evaporated under reduced pressure using a rotary evaporator, and cold water $(15 \mathrm{~mL})$ was added, and solid precipitates obtained were filtered and washed with cold water. The crude product was recrystallized in absolute ethanol.

Synthesis of 2-(isonicotinamido)-1,3-dioxoisoindoline-5-carboxylic acid (7):

A mixture of phthalic anhydride 1 (1 eq.) and isoniazid 3 (1.1 eq.) was dissolved in a $2 \mathrm{~mL}$ of DMSO in a microwave glass vial. The reaction vial was then irradiated to $150{ }^{\circ} \mathrm{C}$ for $10 \mathrm{~min}$ in microwave synthesizer. After completion of the reaction as evident from TLC, the vessel contents were poured in water $(20 \mathrm{~mL})$ and solid precipitates obtained were filtered and washed with cold water and recrystallized using absolute ethanol.

Synthesis of N-(((7-chloroquinolin-4-yl)amino)alkyl)-2-(isonicotinamido)-1,3dioxoisoindoline-5-carboxamide (8a-g):

A mixture of 2-(isonicotinamido)-1,3-dioxoisoindoline-5-carboxylic acid 7 (1.0 eq.), $N$-ethyl$\mathrm{N}$-dimethylaminopropyl carbodiimide (EDC) (1.1 eq.), hydroxybenzotriazole (HOBt) (1.2 
eq.) and 4-diisopropylethylamine (DIPEA) (2 eq.) were dissolved in minimum DMF and was stirred for $5 \mathrm{~min}$ at room temperature. Then, quinoline-diamines 2/quinoline-ethanolamines 2' (1.1 eq.) was added to the reaction mixture, and the stirring was continued for $5 \mathrm{~h}$. On completion, DMF was evaporated under vacuum using a rotary evaporator and cold water (15 $\mathrm{mL}$ ) was added. The solid precipitates obtained were filtered and washed with cold water with subsequently re-crystallization in absolute ethanol.

Synthesis of N-(5-(4-(7-chloroquinolin-4-yl)piperazin-1-yl)-1,3-dioxoisoindolin-2yl)isonicotinamide 11:

To a microwave reaction vial was added a solution of 4-fluoro-phthalic anhydride 1 (1.0 eq.) and Isoniazid (1.0 eq.) in $2 \mathrm{~mL}$ of DMSO. After sealing, the vial was heated to $150{ }^{\circ} \mathrm{C}$ for 10 min in the microwave reactor. After the completion of the first step, as clear from TLC, 7chloro-4-(piperazin-1-yl)quinoline $10(1.0 \mathrm{mmol})$ was added in the same reaction vial. The reaction mixture was again heated at $180{ }^{\circ} \mathrm{C}$ for $15 \mathrm{~min}$ in the microwave, and the completion was determined using TLC. When all the reactants consumed, the contents were poured in water $(20 \mathrm{~mL})$ resulting in the precipitation of the desired product. The obtained product was filtered and recrystallized using absolute ethanol.

Synthesis of N-phthaloylamino acids 12:

A mixture of phthalic anhydride 1 (1 eq.) and amino acids 4 (1 eq.) in a small aliquot of glacial acetic acid was placed in a $10 \mathrm{~mL}$ microwave glass vial and irradiated for $10 \mathrm{~min}$. The reaction mixture on completion was treated with cold water to result in a white powder (12), which was filtered, dried and recrystallized from ethanol.

Synthesis of $\quad N^{\prime}-(2-(1,3-d i o x o i s o i n d o l i n-2-y l) a c e t y l) i s o n i c o t i n o h y d r a z i d e / N^{\prime}-(4-(1,3-$ dioxoisoindolin-2-yl)benzoyl)isonicotinohydrazide (13a-b):

1.0 equivalent of $N$-phthaloylamino acids, $N$-ethyl- $N$-dimethylaminopropyl carbodiimide (EDC) (1.1 eq.), hydroxybenzotriazole (HOBt) (1.2 eq.) and 4-Dimethylaminopyridine (DMAP) (0.2 eq.) were mixed in minimum DMF and the obtained mixture, was stirred for 5 min. Isoniazid (1.1 eq.) was added to the reaction mixture and the stirring was continued for 3 $\mathrm{h}$ at room temperature. DMF was evaporated using a rotary evaporator, and cold water (15 $\mathrm{mL}$ ) was added. The solid precipitates thus obtained were filtered, washed with cold water and recrystallized in absolute ethanol.

Methods for assessment of the anti-tubercular activity of test compounds: 
Bacterial strains and growth conditions: M. tuberculosis $\mathrm{mc}^{2} 6230$ [1] was grown at $37^{\circ} \mathrm{C}$ in Middlebrook 7H9 supplemented with oleic-albumin-dextrose-catalase enrichment (OADC) and $109 \mu \mathrm{M}$ of pantothenic acid (complete $7 \mathrm{H} 9$ ).

Drug susceptibility testing: The vulnerability of M. tuberculosis $\mathrm{mc}^{2} 6230$ to the synthesized compounds was determined as reported previously [2]. Briefly, an exponentially growing culture was diluted in complete $7 \mathrm{H} 9$ to $\mathrm{OD}_{600}=0.01$. The bacteria were then seeded in 100 $\mu \mathrm{L}$ volumes in all the wells of a 96-well plate except the first column of wells which contained $200 \mu \mathrm{L}$ of the bacterial suspension. Compounds (stock concentration $10 \mathrm{mg} / \mathrm{mL}$ ) were directly added to the wells of the first column to achieve a concentration of $200 \mu \mathrm{g} / \mathrm{mL}$. Two-fold serial dilutions were then carried out by transferring $100 \mu \mathrm{L}$ of bacterial suspension from the first column of wells to the second column, mixing, and repeating this procedure for each consecutive column. The plates were then placed in sealed plastic bags and incubated at $37^{\circ} \mathrm{C}$. After 7 days of incubation, plates were visually inspected to determine the MIC, which was defined as the minimal concentration of compound at which no growth of bacteria was observed. In addition, $10 \mu \mathrm{L}$ of resazurin $(0.025 \%$ w/v) (Sigma, Germany) was added to each well and left to incubate for $24 \mathrm{~h}$ to determine metabolic activity of remaining bacteria. If the colour remains blue, bacteria are dead/metabolically inactive, while if there is a colour shift to bright pink, bacteria are alive and metabolically active (Graphical abstract).

\section{Cytotoxicity assay}

Cell viability was determined using Vero cells (ATCC, Sigma, Germany) grown in RPMI medium (Gibco, USA), supplemented with 10\% decomplemented fetal calf serum, under a $5 \% \mathrm{CO}_{2}$ atmosphere. Cells were seeded in 96-well plates at a density of $2 \times 10^{4}$ cells/well in $160 \mu \mathrm{L}$ RPMI medium and incubated overnight at $37^{\circ} \mathrm{C}$ to allow cells to adhere. Compounds (dissolved in DMSO) were freshly diluted to appropriate concentrations in RPMI, to allow the addition of $20 \mu \mathrm{L}$ volumes of the diluted compounds to the cells that resulted in serial dilutions ranging from $100 \mu \mathrm{g} / \mathrm{mL}$ to $0.78 \mu \mathrm{g} / \mathrm{mL}$. The maximum final concentration of DMSO was $1 \%(\mathrm{v} / \mathrm{v})$, and no cytotoxic effect of DMSO was observed at this concentration. After $24 \mathrm{~h}$ incubation at $37^{\circ} \mathrm{C}, 10 \mu \mathrm{L}$ of resazurin $(0.025 \% \mathrm{w} / \mathrm{v})$ (Sigma, Germany) was added to each well, and the cells were incubated for an additional $3 \mathrm{~h}$ at $37^{\circ} \mathrm{C}$. Fluorescence was measured in a Polarstar Omega fluorometer using appropriate filters (540 nm excitation and $590 \mathrm{~nm}$ emission wavelength). Percentage survival was determined by dividing fluorescence values obtained in the compound containing wells by values obtained for control wells containing cells incubated with a dilution series of DMSO and multiplying this value by 
100. The $\mathrm{IC}_{50}$ is defined as the lowest concentration of compound tested at which at least $50 \%$ cell viability was observed.

\section{References}

1. V.K. Sambandamurthy, S. C. Derrick, T. Hsu, B. Chen, M. H. Larsen, K. V. Jalapathy, M. Chen, J. Kim, S. A. Porcelli, J. Chan, S. L. Morris, W. R. Jr. Jacobs, Vaccine. 24 (2006) 6309.

2. J. Ollinger, M. A. Bailey, G. C. Moraski, A. Casey, S. Florio, T. Alling, M. J. Miller, T. Parish, PLoS One, 8 (2013) e60531.

2-(2-((7-chloroquinolin-4-yl)amino)ethyl)-1,3-dioxoisoindoline-5-carboxylic acid (5a): Pale yellow solid; mp 298-299 ${ }^{\circ}$; ${ }^{1} \mathrm{H}$ NMR (400 MHz, DMSO-d $\left.{ }_{6}\right) \delta$ 3.57-3.61 (m, 2H, -CH $\mathbf{C}^{-}$); $3.80\left(\mathrm{t}, J=5.9 \mathrm{~Hz}, 2 \mathrm{H},-\mathbf{C H}_{2^{-}}\right) ; 6.66(\mathrm{~d}, J=5.6 \mathrm{~Hz}, 1 \mathrm{H}, \mathrm{Ar}-\mathrm{H}) ; 7.42(\mathrm{dd}, J=8.8 \mathrm{~Hz}, 2.2 \mathrm{~Hz}, 1 \mathrm{H}$, Ar-H); 7.70 (t, J=6.0 Hz, 1H, NH-exchangeable with $\mathrm{D}_{2} \mathrm{O}$ ); 7.78 (d, J=2.3 Hz, 1H, Ar-H); 7.89-7.92 (m, 1H, Ar-H); 8.02 (d, J=9.0 Hz, 1H, Ar-H); 8.16 (d, J=1.2 Hz, 1H, Ar-H); 8.28$8.31(\mathrm{~m}, 1 \mathrm{H}, \mathrm{Ar}-\mathrm{H}) ; 8.42(\mathrm{~d}, J=5.6 \mathrm{~Hz}, 1 \mathrm{H}, \mathrm{Ar}-\mathrm{H}) ;{ }^{13} \mathrm{C} \mathrm{NMR}\left(100 \mathrm{MHz}, \mathrm{DMSO}-\mathrm{d}_{6}\right) \delta 37.5$, 43.3, 98.8, 117.3, 123.0, 123.2, 124.8, 125.4, 125.7, 134.6, 135.8, 137.5, 138.0, 146.2, 149.7, 151.1, 155.9, 165.5, 166.8, 167.6 HRMS Calcd for $\mathrm{C}_{20} \mathrm{H}_{14} \mathrm{ClN}_{3} \mathrm{O}_{4}[\mathrm{M}+\mathrm{H}]^{+} 396.0673$ found 396.0686.

2-(3-((7-chloroquinolin-4-yl)amino)propyl)-1,3-dioxoisoindoline-5-carboxylic acid (5b): Pale yellow solid; mp 294-295 ${ }^{\circ}$; ${ }^{1} \mathrm{H}$ NMR (400 MHz, DMSO-d 6 ) $\delta$ 1.97-2.03 (m, 2H, - $\mathbf{C H}_{2}$ ); 3.55-3.60 (m, 2H, - $\mathbf{C H}_{2-}$ ); 3.79 (t, $\left.J=5.8 \mathrm{~Hz}, 2 \mathrm{H},-\mathbf{C H}_{2^{-}}\right) ; 6.65$ (d, J=5.7 Hz, 1H, Ar-H); 7.41(dd, $J=8.9 \mathrm{~Hz}, 2.1 \mathrm{~Hz}, 1 \mathrm{H}, \mathrm{Ar}-\mathrm{H}) ; 7.69\left(\mathrm{t}, J=6.1 \mathrm{~Hz}, 1 \mathrm{H}, \mathrm{NH}\right.$-exchangeable with $\left.\mathrm{D}_{2} \mathrm{O}\right)$; $7.76(\mathrm{~d}, J=2.2 \mathrm{~Hz}, 1 \mathrm{H}, \mathrm{Ar}-\mathrm{H}) ; 7.87-7.91(\mathrm{~m}, 1 \mathrm{H}, \mathrm{Ar}-\mathrm{H}) ; 8.00$ (d, J=9.1 Hz, 1H, Ar-H); 8.14 (d, $J=1.4 \mathrm{~Hz}, 1 \mathrm{H}, \mathrm{Ar}-\mathrm{H}) ; 8.25-8.29$ (m, $1 \mathrm{H}, \mathrm{Ar}-\mathrm{H}) ; 8.41$ (d, J=5.4 Hz, 1H, Ar-H); ${ }^{13} \mathrm{C} \mathrm{NMR}$ $\left(100 \mathrm{MHz}, \mathrm{DMSO}-\mathrm{d}_{6}\right) \delta$ 28.5, 36.3, 43.1, 98.6, 117.2, 123.1, 123.3, 124.6, 125.3, 125.6, 134.4, 135.7, 137.4, 138.1, 146.0, 149.6, 151.0, 155.7, 165.3, 166.6, 167.5 HRMS Calcd for $\mathrm{C}_{21} \mathrm{H}_{16} \mathrm{ClN}_{3} \mathrm{O}_{4}[\mathrm{M}+\mathrm{H}]^{+} 410.0829$ found 410.0836 .

2-(4-((7-chloroquinolin-4-yl)amino)butyl)-1,3-dioxoisoindoline-5-carboxylic acid (5c): Pale yellow solid; mp 285-286 ${ }^{\circ} \mathrm{C} ;{ }^{1} \mathrm{H}$ NMR (400 MHz, DMSO-d 6 ) $\delta$ 1.62-1.65 (m, 4H, 2x-CH- ); 3.50-3.53 (m, 2H, - $\left.\mathbf{C H}_{2^{-}}\right) ; 3.60$ (t, J=5.7 Hz, 2H, - $\mathbf{C H}_{2^{-}}$); 6.64 (d, J=5.6 Hz, 1H, Ar-H); 7.40 (dd, $J=8.8 \mathrm{~Hz}, 2.0 \mathrm{~Hz}, 1 \mathrm{H}, \mathrm{Ar}-\mathrm{H}) ; 7.68$ (t, $J=6.0 \mathrm{~Hz}, 1 \mathrm{H}, \mathrm{NH}$-exchangeable with $\mathrm{D}_{2} \mathrm{O}$ ); 7.77 
(d, J=2.1 Hz, 1H, Ar-H); 7.86-7.90 (m, 1H, Ar-H); 8.01 (d, J=9.0 Hz, 1H, Ar-H); 8.15 (d, $J=1.3 \mathrm{~Hz}, 1 \mathrm{H}, \mathrm{Ar}-\mathrm{H}) ; 8.26-8.30$ (m, 1H, Ar-H); 8.42 (d, J=5.4 Hz, 1H, Ar-H); ${ }^{13} \mathrm{C}$ NMR (100 MHz, DMSO-d $\left.{ }_{6}\right) \delta 25.4,25.5,35.2,42.5,98.4,117.1,123.2,123.4,124.7,125.2,125.7$, 134.5, 135.8, 137.3, 138.2, 146.0, 149.4, 151.1, 155.6, 165.3, 166.5, 167.4 HRMS Calcd for $\mathrm{C}_{22} \mathrm{H}_{18} \mathrm{ClN}_{3} \mathrm{O}_{4}[\mathrm{M}+\mathrm{H}]^{+} 424.0986$ found 424.0994 .

2-(6-((7-chloroquinolin-4-yl)amino)hexyl)-1,3-dioxoisoindoline-5-carboxylic acid (5d): Pale yellow solid; mp 272-273 ${ }^{\circ} \mathrm{C} ;{ }^{1} \mathrm{H}$ NMR (400 MHz, DMSO-d 6 ) $\delta$ 1.26-1.41 (m, 4H, 2x-CH- ); 1.52-1.64 (m, 4H, 2x- $\mathbf{C H}_{2^{-}}$); 3.44-3.51 (m, 2H, - $\mathbf{C H}_{2^{-}}$); 3.58 (t, J=5.8 Hz, 2H, - $\left.\mathbf{C H}_{2^{-}}\right) ; 6.63$ (d, J=5.6 Hz, 1H, Ar-H); 7.40 (dd, J=8.9 Hz, 2.1 Hz, 1H, Ar-H); 7.65 (t, J=6.0 Hz, 1H, NHexchangeable with $\left.\mathrm{D}_{2} \mathrm{O}\right) ; 7.76(\mathrm{~d}, J=2.0 \mathrm{~Hz}, 1 \mathrm{H}, \mathrm{Ar}-\mathrm{H}) ; 7.86-7.91(\mathrm{~m}, 1 \mathrm{H}, \mathrm{Ar}-\mathrm{H}) ; 8.01$ (d, $J=9.1 \mathrm{~Hz}, 1 \mathrm{H}, \mathrm{Ar}-\mathrm{H}) ; 8.14$ (d, $J=1.4 \mathrm{~Hz}, 1 \mathrm{H}, \mathrm{Ar}-\mathrm{H}) ; 8.24-8.30$ (m, 1H, Ar-H); 8.41 (d, $J=5.3$ $\mathrm{Hz}, 1 \mathrm{H}, \mathrm{Ar}-\mathrm{H}) ;{ }^{13} \mathrm{C}$ NMR (100 MHz, DMSO-d 6 ) $\delta$ 26.2, 26.3, 28.5, 28.6, 35.1, 42.4, 98.6, $117.3,123.4,123.6,124.8,125.2$, 125.6, 134.4, 135.9, 137.4, 138.3, 146.1, 149.6, 151.2, 155.5, 165.3, 166.4, 167.5 HRMS Calcd for $\mathrm{C}_{24} \mathrm{H}_{22} \mathrm{ClN}_{3} \mathrm{O}_{4}[\mathrm{M}+\mathrm{H}]^{+} 452.1299$ found 452.1309 .

2-(8-((7-chloroquinolin-4-yl)amino)octyl)-1,3-dioxoisoindoline-5-carboxylic acid (5e): yellow solid; mp $245-246{ }^{\circ} \mathrm{C}$; ${ }^{1} \mathrm{H}$ NMR (400 MHz, DMSO-d 6 ) $\delta$ 1.23-1.35 (m, 8H, 4x-CH2-); 1.50-1.62 (m, 4H, 2x- $\mathbf{C H}_{2^{-}}$); 3.28-3.47 (m, 2H, - $\mathbf{C H}_{2^{-}}$); 3.56 (t, J=5.9 Hz, 2H, - $\left.\mathbf{C H}_{2^{-}}\right)$; 6.65 (d, J=5.5 Hz, 1H, Ar-H); 7.41 (dd, J=9.0 Hz, 2.1 Hz, 1H, Ar-H); 7.63 (t, J=6.0 Hz, 1H, NHexchangeable with $\left.\mathrm{D}_{2} \mathrm{O}\right) ; 7.74(\mathrm{~d}, J=2.1 \mathrm{~Hz}, 1 \mathrm{H}, \mathrm{Ar}-\mathrm{H}) ; 7.83-7.90(\mathrm{~m}, 1 \mathrm{H}, \mathrm{Ar}-\mathrm{H}) ; 8.00$ (d, $J=9.0 \mathrm{~Hz}, 1 \mathrm{H}, \mathrm{Ar}-\mathrm{H}) ; 8.15$ (d, $J=1.2 \mathrm{~Hz}, 1 \mathrm{H}, \mathrm{Ar}-\mathrm{H}) ; 8.22-8.29$ (m, 1H, Ar-H); 8.40 (d, J=5.4 $\mathrm{Hz}, 1 \mathrm{H}, \mathrm{Ar}-\mathrm{H}) ;{ }^{13} \mathrm{C} \mathrm{NMR}\left(100 \mathrm{MHz}, \mathrm{DMSO}-\mathrm{d}_{6}\right) \delta$ 26.4, 26.7, 28.3, 28.6, 29.7, 29.8, 35.0, 42.3, 98.8, 117.2, 123.3, 123.7, 124.9, 125.1, 125.4, 134.2, 135.7, 137.1, 138.3, 146.2, 149.5, 151.3, 155.5, 165.2, 166.4, 167.4 HRMS Calcd for $\mathrm{C}_{26} \mathrm{H}_{26} \mathrm{ClN}_{3} \mathrm{O}_{4}[\mathrm{M}+\mathrm{H}]^{+} 480.1612$ found 480.1627 .

2-(2-((7-chloroquinolin-4-yl)amino)ethyl)- $N^{\prime}$-isonicotinoyl-1,3-dioxoisoindoline-5-

carbohydrazide (6a): Yellow solid; mp $182-183{ }^{\circ} \mathrm{C}$; ${ }^{1} \mathrm{H}$ NMR (400 MHz, DMSO-d 6 ) $\delta 3.56-$ 3.60 (m, 2H, - $\left.\mathbf{C H}_{2^{-}}\right) ; 3.82$ (t, J=6.8 Hz, 2H, - $\mathbf{C H}_{2^{-}}$); 6.62 (d, J=5.3 Hz, 1H, Ar-H); 7.39 (dd, $J=9.1 \mathrm{~Hz}, 2.1 \mathrm{~Hz}, 1 \mathrm{H}, \mathrm{Ar}-\mathrm{H}) ; 7.48\left(\mathrm{t}, J=5.9 \mathrm{~Hz}, 1 \mathrm{H}\right.$, NH-exchangeable with $\left.\mathrm{D}_{2} \mathrm{O}\right) ; 7.76$ (d, $J=2.2 \mathrm{~Hz}, 1 \mathrm{H}, \mathrm{Ar}-\mathrm{H}) ; 7.78-7.80$ (m, 2H, Ar-H); 7.98-8.01 (m, 2H, Ar-H); 8.27-8.31 (m, 2H, Ar-H); 8.40 (s, 1H, Ar-H); 8.76 (d, J=4.2 Hz, 2H, Ar-H); 10.98 (s, 2H, NH-exchangeable with $\left.\mathrm{D}_{2} \mathrm{O}\right) ;{ }^{13} \mathrm{C}$ NMR (100 MHz, DMSO-d $\left.{ }_{6}\right) \delta 36.5,40.7,99.1,118.1,121.8,121.9,123.9$, 
$124.3,124.8,128.0,132.8,133.9,134.2,135.0,137.8,139.7,149.5,150.3,151.0,152.4$, 164.6, 164.7, 167.7, 167.8 HRMS Calcd for $\mathrm{C}_{26} \mathrm{H}_{19} \mathrm{ClN}_{6} \mathrm{O}_{4}[\mathrm{M}+\mathrm{H}]^{+} 515.1156$ found 515.1177 .

2-(3-((7-chloroquinolin-4-yl)amino)propyl)-N'-isonicotinoyl-1,3-dioxoisoindoline-5-

carbohydrazide (6b): Yellow solid; mp $175-176^{\circ} \mathrm{C}$; ${ }^{1} \mathrm{H}$ NMR (400 MHz, DMSO- $\left.\mathrm{d}_{6}\right) \delta 1.99-$ 2.05 (m, 2H, - $\left.\mathbf{C H}_{2^{-}}\right) ; 3.31-3.38$ (m, 2H, - $\mathbf{C H}_{2^{-}}$); 3.72 (t, J=6.8 Hz, 2H, - $\mathbf{C H}_{2^{-}}$); 6.44 (d, J=5.5 $\mathrm{Hz}, 1 \mathrm{H}, \mathrm{Ar}-\mathrm{H}) ; 7.23$ (t, J=5.5 Hz, 1H, NH-exchangeable with $\left.\mathrm{D}_{2} \mathrm{O}\right) ; 7.39(\mathrm{~d}, J=9.1 \mathrm{~Hz}, 1 \mathrm{H}$, Ar-H); 7.73 (s, 1H, Ar-H); 7.79 (d, J=5.6 Hz, 2H, Ar-H); 7.96 (d, J=8.1 Hz, 1H, Ar-H); 8.17 (d, J=9.1 Hz, 1H, Ar-H); 8.24-8.35 (m, 2H, Ar-H); 8.35 (d, J=5.4 Hz, 1H, Ar-H); 8.76 (d, $J=5.2 \mathrm{~Hz}, 2 \mathrm{H}, \mathrm{Ar}-\mathrm{H}) ; 10.91$ (s, $1 \mathrm{H}, \mathrm{NH}$-exchangeable with $\left.\mathrm{D}_{2} \mathrm{O}\right) ;{ }^{13} \mathrm{C}$ NMR $(100 \mathrm{MHz}$, DMSO-d $\left.{ }_{6}\right) \delta 27.1,36.4,40.6,99.3,117.9,121.8,121.9,123.9,124.60,124.67,127.8,132.7$, $134.0,134.2$, 135.0, 137.7, 139.8, 149.3, 150.6, 151.0, 152.2, 164.6, 164.8, 167.92, 167.93 HRMS Calcd for $\mathrm{C}_{27} \mathrm{H}_{21} \mathrm{ClN}_{6} \mathrm{O}_{4}[\mathrm{M}+\mathrm{H}]^{+} 529.1313$ found 529.1334 .

2-(4-((7-chloroquinolin-4-yl)amino)butyl)-N'-isonicotinoyl-1,3-dioxoisoindoline-5-

carbohydrazide (6c): Yellow solid; mp $162-163{ }^{\circ} \mathrm{C} ;{ }^{1} \mathrm{H}$ NMR (400 MHz, DMSO- $\left.\mathrm{d}_{6}\right) \delta 1.65-$ 1.68 (m, 4H, 2x- $\mathbf{C H}_{2^{-}}$); 3.29-3.35 (m, 2H, - $\mathbf{C H}_{2^{-}}$); 3.70 (t, J=6.6 Hz, 2H, - $\mathbf{C H}_{2^{-}}$); 6.42 (d, $J=5.4 \mathrm{~Hz}, 1 \mathrm{H}, \mathrm{Ar}-\mathrm{H}) ; 7.21\left(\mathrm{t}, J=5.5 \mathrm{~Hz}, 1 \mathrm{H}, \mathrm{NH}\right.$-exchangeable with $\left.\mathrm{D}_{2} \mathrm{O}\right) ; 7.37(\mathrm{~d}, J=9.0 \mathrm{~Hz}$, 1H, Ar-H); 7.71 (s, 1H, Ar-H); 7.78 (d, J=5.7 Hz, 2H, Ar-H); 7.94 (d, J=8.2 Hz, 1H, Ar-H); 8.15 (d, J=9.0 Hz, 1H, Ar-H); 8.21-8.32 (m, 2H, Ar-H); 8.34 (d, J=5.5 Hz, 1H, Ar-H); 8.77 (d, $J=5.2 \mathrm{~Hz}, 2 \mathrm{H}, \mathrm{Ar}-\mathrm{H}) ; 10.89$ (s, 1H, NH-exchangeable with $\left.\mathrm{D}_{2} \mathrm{O}\right) ;{ }^{13} \mathrm{C}$ NMR $(100 \mathrm{MHz}$, DMSO- $\left.\mathrm{d}_{6}\right) \delta 25.6,25.9,35.9,40.4,99.2,117.7,121.6,121.8,123.6,124.4,124.8,127.7$, $132.6,134.1,134.4,135.2,137.8,139.6,149.2$, 150.4, 151.1, 152.3, 164.6, 164.9, 167.5, 167.6 HRMS Calcd for $\mathrm{C}_{28} \mathrm{H}_{23} \mathrm{ClN}_{6} \mathrm{O}_{4}[\mathrm{M}+\mathrm{H}]^{+} 543.1469$ found 543.1487.

2-(6-((7-chloroquinolin-4-yl)amino)hexyl)- $N$ '-isonicotinoyl-1,3-dioxoisoindoline-5-

carbohydrazide (6d): Yellow solid; mp $158-159{ }^{\circ} \mathrm{C}$; ${ }^{1} \mathrm{H}$ NMR (400 MHz, DMSO-d 6 ) $\delta 1.22-$

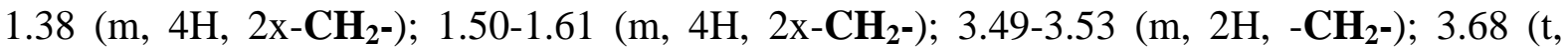
$\left.J=6.7 \mathrm{~Hz}, 2 \mathrm{H},-\mathbf{C H}_{2}-\right) ; 6.40(\mathrm{~d}, J=5.4 \mathrm{~Hz}, 1 \mathrm{H}, \mathrm{Ar}-\mathrm{H}) ; 7.20(\mathrm{t}, J=5.4 \mathrm{~Hz}, 1 \mathrm{H}, \mathrm{NH}-$ exchangeable with $\left.\mathrm{D}_{2} \mathrm{O}\right) ; 7.36(\mathrm{~d}, J=9.0 \mathrm{~Hz}, 1 \mathrm{H}, \mathrm{Ar}-\mathrm{H}) ; 7.73(\mathrm{~s}, 1 \mathrm{H}, \mathrm{Ar}-\mathrm{H}) ; 7.77$ (d, J=5.7 Hz, 2H, Ar-H); 7.93 (d, J=8.3 Hz, 1H, Ar-H); 8.16 (d, J=9.1 Hz, 1H, Ar-H); 8.20-8.32 (m, 2H, Ar-H); 8.32 (d, J=5.6 Hz, 1H, Ar-H); 8.79 (d, J=5.3 Hz, 2H, Ar-H); 10.90 (s, 1H, NHexchangeable with $\left.\mathrm{D}_{2} \mathrm{O}\right) ;{ }^{13} \mathrm{C}$ NMR (100 MHz, DMSO-d $\left.{ }_{6}\right) \delta 26.3,26.7,28.4,28.6,36.7$, $40.1,99.3,117.7,121.5,121.8,123.4,124.5,124.9,127.6,132.8,134.3,134.4,135.5,137.5$, 
139.8, 149.1, 150.5, 151.3, 152.4, 164.5, 164.9, 167.4, 167.7 HRMS Calcd for $\mathrm{C}_{30} \mathrm{H}_{27} \mathrm{ClN}_{6} \mathrm{O}_{4}$ $[\mathrm{M}+\mathrm{H}]^{+} 571.1782$ found 571.1793 .

2-(8-((7-chloroquinolin-4-yl)amino)octyl)- $N^{\prime}$-isonicotinoyl-1,3-dioxoisoindoline-5-

carbohydrazide (6e): Yellow solid; mp $141-142{ }^{\circ} \mathrm{C} ;{ }^{1} \mathrm{H}$ NMR (400 MHz, DMSO-d $\left.\mathrm{d}_{6}\right) \delta 1.20-$ $1.36\left(\mathrm{~m}, 8 \mathrm{H}, 4 \mathrm{x}-\mathbf{C H}_{2^{-}}\right) ; 1.52-1.65\left(\mathrm{~m}, 4 \mathrm{H}, 2 \mathrm{x}-\mathbf{C H}_{2^{-}}\right)$; 3.29-3.45 (m, 2H, - $\left.\mathbf{C H}_{2^{-}}\right)$; 3.59 (t, $\left.J=6.5 \mathrm{~Hz}, 2 \mathrm{H},-\mathbf{C H}_{2^{-}}\right) ; 6.39$ (d, J=5.5 Hz, 1H, Ar-H); 7.19 (t, J=5.4 Hz, 1H, NHexchangeable with $\left.\mathrm{D}_{2} \mathrm{O}\right) ; 7.34(\mathrm{~d}, J=8.9 \mathrm{~Hz}, 1 \mathrm{H}, \mathrm{Ar}-\mathrm{H}) ; 7.72(\mathrm{~s}, 1 \mathrm{H}, \mathrm{Ar}-\mathrm{H}) ; 7.75$ (d, J=5.6 $\mathrm{Hz}, 2 \mathrm{H}, \mathrm{Ar}-\mathrm{H}) ; 7.94$ (d, J=8.3 Hz, 1H, Ar-H); 8.14 (d, J=9.0 Hz, 1H, Ar-H); 8.22-8.32 (m, 2H, Ar-H); 8.34 (d, J=5.5 Hz, 1H, Ar-H); 8.78 (d, J=5.4 Hz, 2H, Ar-H); 10.90 (s, 1H, NHexchangeable with $\left.\mathrm{D}_{2} \mathrm{O}\right) ;{ }^{13} \mathrm{C}$ NMR (100 MHz, DMSO-d $\left.{ }_{6}\right) \delta 26.4,26.6,28.7,28.9,29.5$, 29.8, 35.9, 40.4, 99.1, 117.5, 121.7, 121.9, 123.4, 124.8, 125.1, 127.3, 132.7, 134.3, 134.6, 135.7, 137.6, 139.9, 149.0, 150.6, 151.2, 152.5, 164.4, 164.8, 167.3, 167.6 HRMS Calcd for $\mathrm{C}_{32} \mathrm{H}_{31} \mathrm{ClN}_{6} \mathrm{O}_{4}[\mathrm{M}+\mathrm{H}]^{+} 599.2095$ found 599.2082.

2-benzamido-1,3-dioxoisoindoline-5-carboxylic acid (7): Light yellow solid; mp $>300{ }^{\circ} \mathrm{C} ;{ }^{1} \mathrm{H}$ NMR (400 MHz, DMSO-d ${ }_{6}$ ) 7.83-7.84 (m, 2H, Ar-H); 8.10-8.12 (m, 1H, Ar-H); 8.32-8.33 (m, 1H, Ar-H); 8.42-8.44 (m, 1H, Ar-H); 8.81-8.82 (m, 2H, Ar-H); $11.78(\mathrm{~s}, 1 \mathrm{H}, \mathrm{NH}-$ exchangeable with $\mathrm{D}_{2} \mathrm{O}$ ); HRMS Calcd for $\mathrm{C}_{16} \mathrm{H}_{10} \mathrm{~N}_{2} \mathrm{O}_{5}[\mathrm{M}+\mathrm{H}]^{+} 311.0590$ found 311.0598 .

N-(2-((7-chloroquinolin-4-yl)amino)ethyl)-2-(isonicotinamido)-1,3-dioxoisoindoline-5carboxamide (8a): Brown solid; mp 186-187 ${ }^{\circ} \mathrm{C} ;{ }^{1} \mathrm{H}$ NMR (400 MHz, DMSO-d $\left.\mathrm{d}_{6}\right) \delta 3.52-3.59$ (m, 2H, - $\mathbf{C H}_{2^{-}}$); 3.77-3.85 (m, 2H, - $\left.\mathbf{C H}_{2^{-}}\right) ; 6.63$ (d, J=5.2 Hz, 1H, Ar-H); 7.32-7.44 (m, 2H, Ar-H); 7.72-7.79 (m, 3H, Ar-H); 7.94-8.01 (m, 2H, Ar-H); 8.21-8.41 (m, 3H, Ar-H); 8.70$8.77(\mathrm{~m}, 2 \mathrm{H}, \mathrm{Ar}-\mathrm{H}) ; 10.92$ (s, 1H, NH-exchangeable with $\left.\mathrm{D}_{2} \mathrm{O}\right) ;{ }^{13} \mathrm{C}$ NMR $(100 \mathrm{MHz}$, DMSO-d $\left._{6}\right) \delta 35.2$, 41.6, 106.8, 118.6, 121.2, 122.1, 126.9, 127.2, 129.8, 130.9, 131.8, 136.3, 137.1, 139.6, 140.7, 142.7, 144.3, 151.0, 151.6, 156.7, 161.4, 162.3, 164.6, 172.8 HRMS Calcd for $\mathrm{C}_{26} \mathrm{H}_{19} \mathrm{ClN}_{6} \mathrm{O}_{4}[\mathrm{M}+\mathrm{H}]^{+} 515.1156$ found 515.1171 .

N-(3-((7-chloroquinolin-4-yl)amino)propyl)-2-(isonicotinamido)-1,3-dioxoisoindoline-5carboxamide (8b): Brown solid; mp 181-182 ${ }^{\circ} \mathrm{C}$; ${ }^{1} \mathrm{H}$ NMR (400 MHz, DMSO-d 6 ) $\delta$ 1.80-1.86 $\left(\mathrm{m}, 2 \mathrm{H},-\mathbf{C H}_{2^{-}}\right) ; 3.48-3.51\left(\mathrm{~m}, 2 \mathrm{H},-\mathbf{C H}_{2^{-}}\right) ; 3.74-3.82\left(\mathrm{~m}, 2 \mathrm{H},-\mathbf{C H}_{2^{-}}\right) ; 6.61(\mathrm{~d}, J=5.3 \mathrm{~Hz}, 1 \mathrm{H}$, Ar-H); 7.30-7.41 (m, 2H, Ar-H); 7.71-7.80 (m, 3H, Ar-H); 7.92-8.00 (m, 2H, Ar-H); 8.238.38 (m, 3H, Ar-H); 8.71-8.75 (m, 2H, Ar-H); 10.91 (s, 1H, NH-exchangeable with $\left.\mathrm{D}_{2} \mathrm{O}\right) ;{ }^{13} \mathrm{C}$ NMR (100 MHz, DMSO-d $\left.{ }_{6}\right) \delta$ 28.6, 35.1, 41.6, 105.5, 118.0, 121.3, 122.1, 126.6, 127.0, 
$129.4,130.5,131.5,135.7,136.8,139.2,140.4,142.6,144.4,150.9,151.6,157.1,161.4$, 162.0, 164.2, 172.5 HRMS Calcd for $\mathrm{C}_{27} \mathrm{H}_{21} \mathrm{ClN}_{6} \mathrm{O}_{4}[\mathrm{M}+\mathrm{H}]^{+} 529.1313$ found 529.1326.

N-(4-((7-chloroquinolin-4-yl)amino)butyl)-2-(isonicotinamido)-1,3-dioxoisoindoline-5-

carboxamide (8c): Brown solid; mp 178-179 ${ }^{\circ} \mathrm{C} ;{ }^{1} \mathrm{H}$ NMR (400 MHz, DMSO-d $\left.\mathrm{d}_{6}\right) \delta 1.50-1.61$ $\left(\mathrm{m}, 2 \mathrm{H},-\mathbf{C H}_{2^{-}}\right)$; 1.69-1.75 (m, 2H, - $\left.\mathbf{C H}_{2^{-}}\right)$; 3.35-3.39 (m, 2H, - $\left.\mathbf{C H}_{2^{-}}\right)$; 3.59-3.63 (m, 2H, $\left.\mathbf{C H}_{2^{-}}\right) ; 6.60$ (d, J=5.2 Hz, 1H, Ar-H); 7.32-7.40 (m, 2H, Ar-H); 7.70-7.79 (m, 3H, Ar-H); 7.91-8.01 (m, 2H, Ar-H); 8.24-8.37 (m, 3H, Ar-H); 8.70-8.74 (m, 2H, Ar-H); 10.92 (s, 1H, $\mathrm{NH}$-exchangeable with $\left.\mathrm{D}_{2} \mathrm{O}\right) ;{ }^{13} \mathrm{C}$ NMR (100 MHz, DMSO-d $\left.\mathrm{d}_{6}\right) \delta 26.3,27.1,37.5,40.9$, $105.4,118.1,121.4,122.5,126.4,127.2,129.4,130.6,131.2,135.9,136.7,139.1,140.3$, 142.3, 144.5, 150.7, 151.5, 157.0, 161.2, 162.1, 164.1, 172.2 HRMS Calcd for $\mathrm{C}_{28} \mathrm{H}_{23} \mathrm{ClN}_{6} \mathrm{O}_{4}$ $[\mathrm{M}+\mathrm{H}]^{+} 543.1469$ found 543.1478 .

N-(6-((7-chloroquinolin-4-yl)amino $)$ hexyl)-2-(isonicotinamido)-1,3-dioxoisoindoline-5-

carboxamide (8d): Brown solid; mp 172-173 ${ }^{\circ} \mathrm{C} ;{ }^{1} \mathrm{H}$ NMR (400 MHz, DMSO-d 6 ) $\delta 1.30-1.38$ (m, 4H, 2x- $\left.\mathbf{C H}_{2^{-}}\right)$; 1.54-1.60 (m, 2H, - $\left.\mathbf{C H}_{2^{-}}\right)$; 1.65-1.70 (m, 2H, - $\left.\mathbf{C H}_{2^{-}}\right)$; 3.31-3.39 (m, 2H, $\left.\mathbf{C H}_{2^{-}}\right)$; 3.56-3.59 (m, 2H, - $\left.\mathbf{C H}_{2^{-}}\right)$; 6.61 (d, J=5.3 Hz, 1H, Ar-H); 7.30-7.41 (m, 2H, Ar-H); 7.71-7.78 (m, 3H, Ar-H); 7.91-8.00 (m, 2H, Ar-H); 8.23-8.36 (m, 3H, Ar-H); 8.71-8.74 (m, $2 \mathrm{H}, \mathrm{Ar}-\mathrm{H}) ; 10.92$ (s, 1H, NH-exchangeable with $\left.\mathrm{D}_{2} \mathrm{O}\right) ;{ }^{13} \mathrm{C}$ NMR (100 MHz, DMSO-d $\left.\mathrm{d}_{6}\right) \delta$ 26.1, 27.3, 29.3, 29.7, 38.4, 40.8, 105.3, 118.0, 121.5, 122.4, 126.4, 127.1, 129.3, 130.7, $131.1,135.8,136.6,139.0,140.4,142.5,144.6,150.8,151.6,157.1,161.3,162.0,164.3$, 172.4 HRMS Calcd for $\mathrm{C}_{30} \mathrm{H}_{27} \mathrm{ClN}_{6} \mathrm{O}_{4}[\mathrm{M}+\mathrm{H}]^{+} 571.1782$ found 571.1789.

N-(8-((7-chloroquinolin-4-yl)amino)octyl)-2-(isonicotinamido)-1,3-dioxoisoindoline-5-

carboxamide (8e): Brown solid; mp $165-166^{\circ} \mathrm{C} ;{ }^{1} \mathrm{H}$ NMR (400 MHz, DMSO-d $\left.\mathrm{d}_{6}\right) \delta 1.28-1.39$ (m, 8H, 4x-CH $\left.\mathbf{2}^{-}\right)$; 1.51-1.65 (m, 4H, 2x- $\mathbf{C H}_{2^{-}}$); 3.30-3.36 (m, 2H, - $\mathbf{C H}_{2^{-}}$); 3.54-3.58 (m, 2H, - $\left.\mathbf{C H}_{2^{-}}\right) ; 6.60(\mathrm{~d}, J=5.4 \mathrm{~Hz}, 1 \mathrm{H}, \mathrm{Ar}-\mathrm{H}) ; 7.29-7.41$ (m, 2H, Ar-H); 7.70-7.77 (m, 3H, Ar-H); 7.89-7.99 (m, 2H, Ar-H); 8.21-8.34 (m, 3H, Ar-H); 8.68-8.72 (m, 2H, Ar-H); 10.91 (s, 1H, $\mathrm{NH}$-exchangeable with $\left.\mathrm{D}_{2} \mathrm{O}\right) ;{ }^{13} \mathrm{C}$ NMR $\left(100 \mathrm{MHz}\right.$, DMSO-d $\left.\mathrm{d}_{6}\right) \delta 25.6,27.3,28.5,28.7,29.3$, 29.7, 38.8, 41.6, 105.2, 118.1, 121.6, 122.3, 126.5, 127.0, 129.5, 130.4, 131.0, 135.9, 136.6, 139.0, 140.3, 142.6, 144.8, 150.7, 151.6, 157.0, 161.2, 162.4, 164.2, 172.3 HRMS Calcd for $\mathrm{C}_{32} \mathrm{H}_{31} \mathrm{ClN}_{6} \mathrm{O}_{4}[\mathrm{M}+\mathrm{H}]^{+} 599.2095$ found 599.2103.

2-((7-chloroquinolin-4-yl)amino)ethyl-2-(isonicotinamido)-1,3-dioxoisoindoline-5-

carboxylate (8f): Brown solid; mp 162-163 ${ }^{\circ} \mathrm{C} ;{ }^{1} \mathrm{H}$ NMR (400 MHz, DMSO-d $\left.{ }_{6}\right) \delta 3.68-3.72$ 
(m, 2H, - $\mathbf{C H}_{2^{-}}$); 4.32 (t, J=6.1 Hz, 2H, - $\mathbf{C H}_{2^{-}}$); 6.45 (d, J=5.3 Hz, 1H, Ar-H); 6.52 (t, J=5.8 $\mathrm{Hz}, 1 \mathrm{H}, \mathrm{NH}$-exchangeable with $\left.\mathrm{D}_{2} \mathrm{O}\right) ; 7.35$ (dd, J=9.0 Hz, 2.1 Hz, 1H, Ar-H); 7.74-7.79 (m, $3 \mathrm{H}, \mathrm{Ar}-\mathrm{H}) ; 7.85-7.93$ (m, 2H, Ar-H); 8.20-8.26 (m, 2H, Ar-H); 8.53 (d, J=5.5 Hz, 1H, Ar-H); 8.72-8.78 (m, 2H, Ar-H); 11.01 (s, 1H, NH-exchangeable with $\left.\mathrm{D}_{2} \mathrm{O}\right) ;{ }^{13} \mathrm{C}$ NMR $(100 \mathrm{MHz}$, DMSO-d $\left.{ }_{6}\right) \delta 42.2,60.4,101.6,118.4,121.4,122.4,125.0,125.4,126.6,127.3,132.4,132.7$, 134.7, 135.5, 136.8, 138.4, 147.9, 149.3, 150.1, 150.8, 164.2, 165.1, 165.4, 166.2 HRMS Calcd for $\mathrm{C}_{26} \mathrm{H}_{18} \mathrm{ClN}_{5} \mathrm{O}_{5}[\mathrm{M}+\mathrm{H}]^{+} 516.0996$ found 516.0987.

3-((7-chloroquinolin-4-yl)amino)propyl-2-(isonicotinamido)-1,3-dioxoisoindoline-5carboxylate (8g): Brown solid; mp 156-157 ${ }^{\circ} \mathrm{C} ;{ }^{1} \mathrm{H}$ NMR (400 MHz, DMSO-d 6 ) $\delta$ 1.96-2.01 (m, 2H, - $\left.\mathbf{C H}_{2^{-}}\right) ; 3.57-3.68\left(\mathrm{~m}, 2 \mathrm{H},-\mathbf{C H}_{2^{-}}\right) ; 4.12$ (t, $\left.J=6.2 \mathrm{~Hz}, 2 \mathrm{H},-\mathbf{C H}_{2^{-}}\right) ; 6.44(\mathrm{~d}, J=5.4 \mathrm{~Hz}$, $1 \mathrm{H}, \mathrm{Ar}-\mathrm{H}) ; 6.51\left(\mathrm{t}, J=5.7 \mathrm{~Hz}, 1 \mathrm{H}, \mathrm{NH}\right.$-exchangeable with $\left.\mathrm{D}_{2} \mathrm{O}\right) ; 7.32(\mathrm{dd}, J=8.9 \mathrm{~Hz}, 2.0 \mathrm{~Hz}$, 1H, Ar-H); 7.72-7.77 (m, 3H, Ar-H); 7.84-7.93 (m, 2H, Ar-H); 8.21-8.25 (m, 2H, Ar-H); 8.54 (d, J=5.6 Hz, 1H, Ar-H); 8.70-8.76 (m, 2H, Ar-H); 11.01 (s, 1H, NH-exchangeable with $\left.\mathrm{D}_{2} \mathrm{O}\right) ;{ }^{13} \mathrm{C}$ NMR $\left(100 \mathrm{MHz}, \mathrm{DMSO}-\mathrm{d}_{6}\right) \delta 28.2,42.5,60.1,101.5,118.2,121.4,122.5,125.1$, 125.2 , 126.7, 127.2, 132.3, 132.6, 134.7, 135.6, 136.5, 138.5, 147.8, 149.2, 150.2, 150.9, 164.1, 165.2, 165.3, 166.1 HRMS Calcd for $\mathrm{C}_{27} \mathrm{H}_{20} \mathrm{ClN}_{5} \mathrm{O}_{5}[\mathrm{M}+\mathrm{H}]^{+} 530.1153$ found 530.1166 .

$\mathrm{N}$-(5-fluoro-1,3-dioxoisoindolin-2-yl)benzamide (9): White solid; mp 259-260 ${ }^{\circ} \mathrm{C} ;{ }^{1} \mathrm{H}$ NMR (400 MHz, DMSO-d $\left.{ }_{6}\right) \delta$ 7.74-7.79 (m, 1H, Ar-H); 7.82-7.84 (m, 2H, Ar-H); 7.92-7.94 (m, $1 \mathrm{H}, \operatorname{Ar}-\mathrm{H}) ; 8.06-8.09(\mathrm{~m}, 1 \mathrm{H}, \mathrm{Ar}-\mathrm{H}) ; 8.80-8.82(\mathrm{~m}, 2 \mathrm{H}, \mathrm{Ar}-\mathrm{H}) ; 11.73(\mathrm{~s}, 1 \mathrm{H}, \mathrm{NH}-$ exchangeable with $\left.\mathrm{D}_{2} \mathrm{O}\right) ;{ }^{13} \mathrm{C}$ NMR $\left(100 \mathrm{MHz}, \mathrm{DMSO}-\mathrm{d}_{6}\right) \delta 107.9,114.5,117.8,121.9$, 126.4, 132.9, 138.4, 151.2, 156.2, 164.6, 165.5, 166.2. HRMS Calcd for $\mathrm{C}_{15} \mathrm{H}_{9} \mathrm{FN}_{2} \mathrm{O}_{3}$ $[\mathrm{M}+\mathrm{H}]^{+} 285.0597$ found 285.0585 .

N-(5-(4-(7-chloroquinolin-4-yl)piperazin-1-yl)-1,3-dioxoisoindolin-2-yl)isonicotinamide (11): Yellow solid; mp $152-153{ }^{\circ} \mathrm{C}$; ${ }^{1} \mathrm{H}$ NMR (400 MHz, DMSO-d 6 ) $\delta 3.32-3.34$ (m, 4H, 2x$\mathbf{C H}_{2^{-}}$); 3.75-3.77 (m, 4H, 2x-CH $\left.\mathbf{2}^{-}\right) ; 7.04$ (d, J=5.0 Hz, 1H, Ar-H); 7.38 (dd, J=8.6 Hz, 2.4 $\mathrm{Hz}, 1 \mathrm{H}, \mathrm{Ar}-\mathrm{H}) ; 7.49$ (d, J=2.2 Hz, 1H, Ar-H); 7.54-7.57 (m, 1H, Ar-H); 7.77-7.79 (m, 2H, Ar-H); 7.82-7.83 (m, 2H, Ar-H); 7.97 (d, J=2.2 Hz, 1H, Ar-H); 8.11 (d, J=9.0 Hz, 1H, Ar-H); $8.71(\mathrm{~d}, J=5.0 \mathrm{~Hz}, 1 \mathrm{H}, \mathrm{Ar}-\mathrm{H}) ; 8.80-8.81(\mathrm{~m}, 2 \mathrm{H}, \mathrm{Ar}-\mathrm{H}) ;{ }^{13} \mathrm{C} \mathrm{NMR}\left(100 \mathrm{MHz}, \mathrm{DMSO}-\mathrm{d}_{6}\right) \delta$ 47.1, 53.4, 108.9, 110.0, 117,0, 118.8, 121.9, 126.1, 126.4, 126.6, 128.6, 132.5, 134.2, 138.3, 150.1, 150.9, 151.3, 152.7, 155.8, 156.4, 164.4, 165.4, 166.1 HRMS Calcd for $\mathrm{C}_{27} \mathrm{H}_{21} \mathrm{ClN}_{6} \mathrm{O}_{3}$ $[\mathrm{M}+\mathrm{H}]^{+} 513.1364$ found 513.1387 . 
$N^{\prime}$-(2-(1,3-dioxoisoindolin-2-yl)acetyl)isonicotinohydrazide (13a): White solid; mp 255$256{ }^{\circ} \mathrm{C} ;{ }^{1} \mathrm{H}$ NMR $\left(400 \mathrm{MHz}, \mathrm{DMSO}-\mathrm{d}_{6}\right) \delta 4.32$ (s, 2H, - $\mathbf{C H}_{2^{-}}$); 7.71 (d, J=6.0 Hz, 1H, Ar-H); 7.82-7.91 (m, 4H, Ar-H); 8.71 (d, J=6.0 Hz, 1H, Ar-H); 10.48 (s, 1H, NH-exchangeable with $\mathrm{D}_{2} \mathrm{O}$ ); 10.77 (s, 1H, NH-exchangeable with $\left.\mathrm{D}_{2} \mathrm{O}\right) ;{ }^{13} \mathrm{C}$ NMR (100 MHz, DMSO-d $\left.{ }_{6}\right) \delta 39.4$, 123.8, 123.9, 132.1, 135.2, 143.9, 147.1, 163.0, 166.2, 167.9 HRMS Calcd for $\mathrm{C}_{16} \mathrm{H}_{12} \mathrm{~N}_{4} \mathrm{O}_{4}$ $[\mathrm{M}+\mathrm{H}]^{+} 325.0859$ found 325.0877 .

$N^{\prime}$-(2-(1,3-dioxoisoindolin-2-yl)acetyl)isonicotinohydrazide (13b): White solid; mp 267$268^{\circ} \mathrm{C} ;{ }^{1} \mathrm{H}$ NMR (300 MHz, DMSO-d 6 ) $\delta 7.61$ (s, 1H, Ar-H); 7.80-8.02 (m, 8H, Ar-H); 8.76 (s, $1 \mathrm{H}, \mathrm{Ar}-\mathrm{H}) ; 10.85$ (s, 2H, NH-exchangeable with $\mathrm{D}_{2} \mathrm{O}$ ); HRMS Calcd for $\mathrm{C}_{21} \mathrm{H}_{14} \mathrm{~N}_{4} \mathrm{O}_{4}$ $[\mathrm{M}+\mathrm{H}]^{+} 387.1015$ found 387.1026 .

${ }^{1}$ H NMR of 2-(2-((7-chloroquinolin-4-yl)amino)ethyl)-1,3-dioxoisoindoline-5-carboxylic acid (5a):

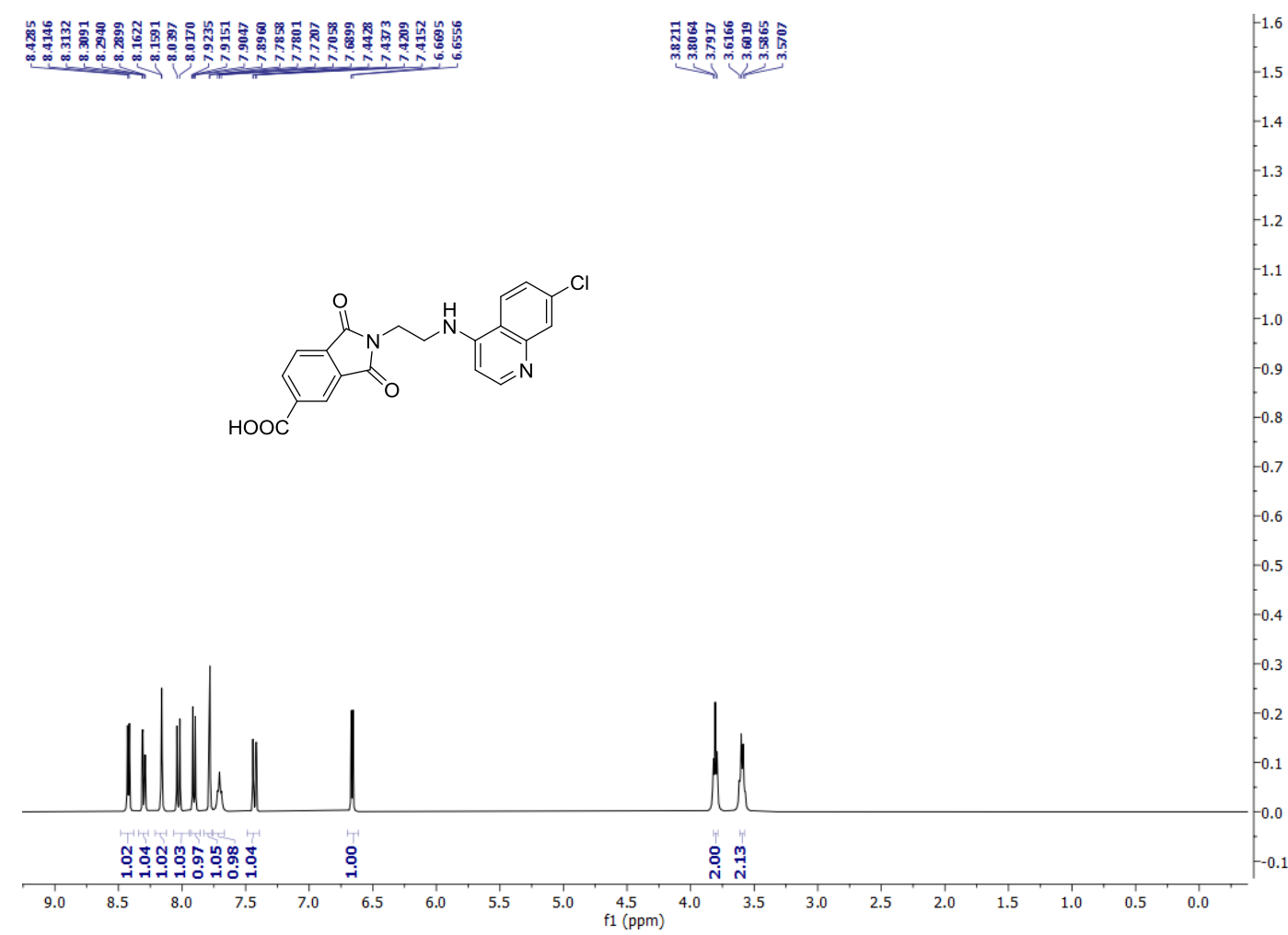

${ }^{13}$ C NMR of 2-(2-((7-chloroquinolin-4-yl)amino)ethyl)-1,3-dioxoisoindoline-5-carboxylic acid (5a): 


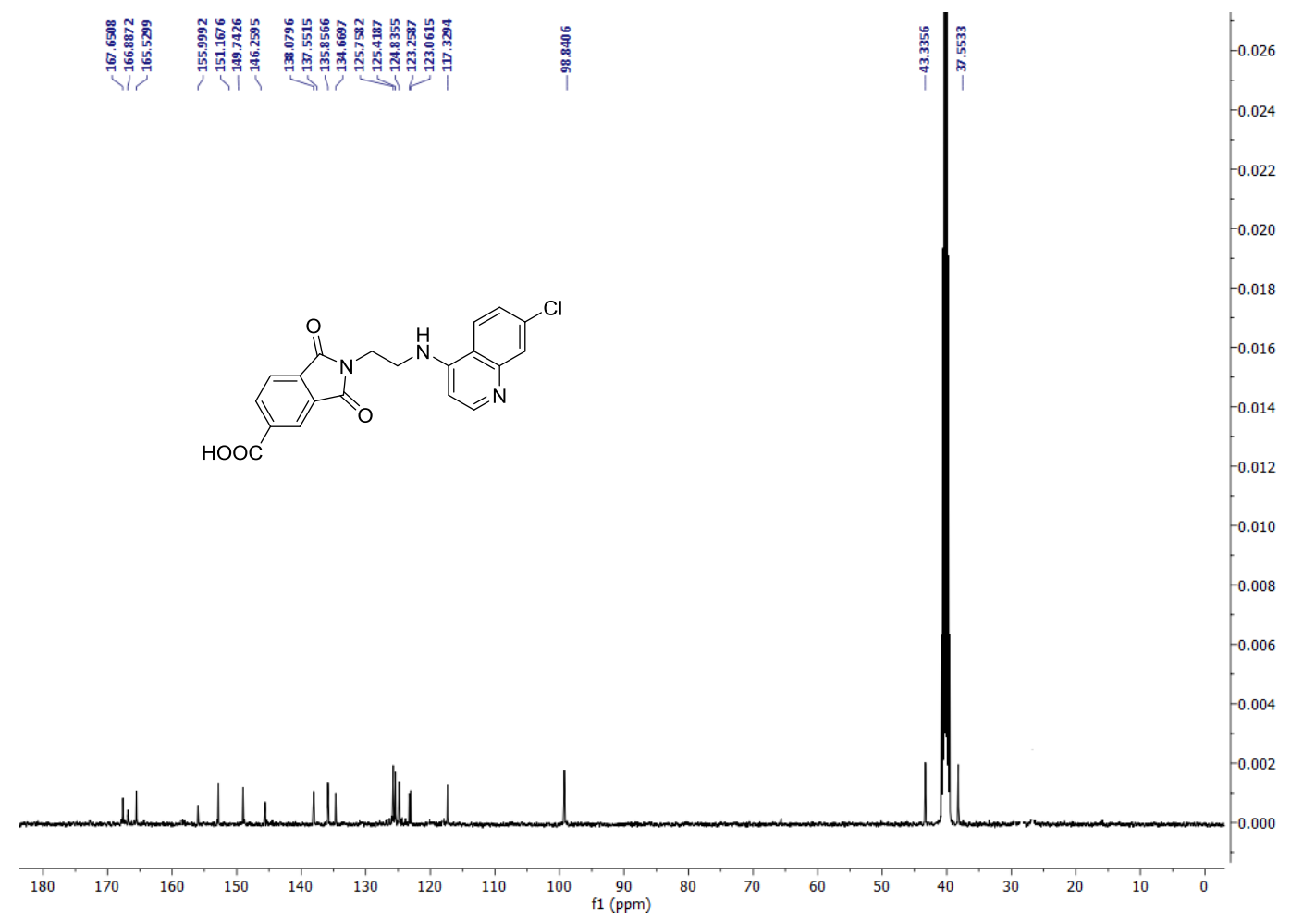

${ }^{1} \mathrm{H}$ NMR of 2-(2-((7-chloroquinolin-4-yl)amino)ethyl)-N'-isonicotinoyl-1,3dioxoisoindoline-5-carbohydrazide (6a):

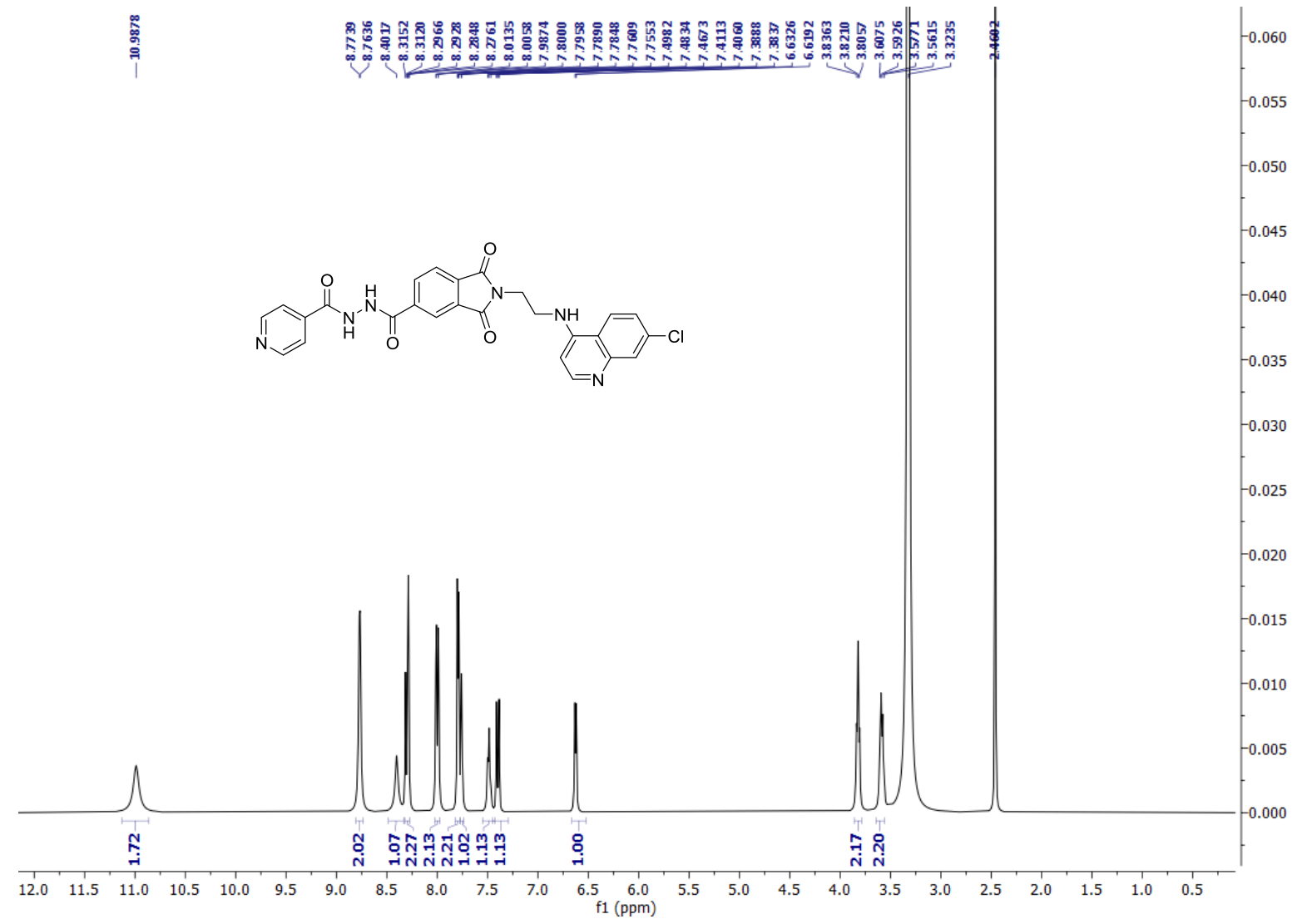

${ }^{13} \mathrm{C} \quad \mathrm{NMR}$ of 2-(2-((7-chloroquinolin-4-yl)amino)ethyl)-N'-isonicotinoyl-1,3dioxoisoindoline-5-carbohydrazide (6a): 


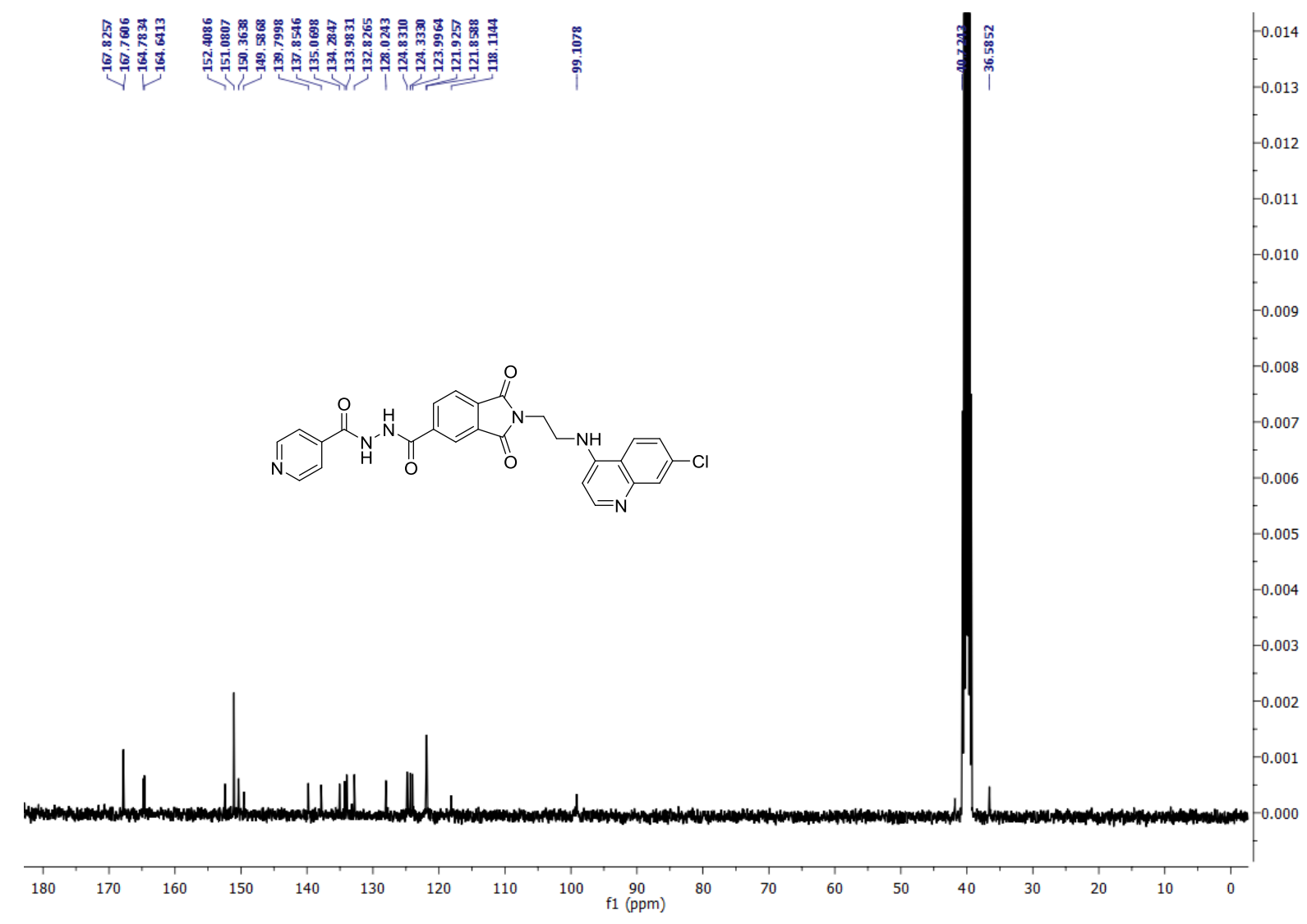

${ }^{1}$ H NMR of 2-(3-((7-chloroquinolin-4-yl)amino)propyl)-N'-isonicotinoyl-1,3dioxoisoindoline-5-carbohydrazide (6b):

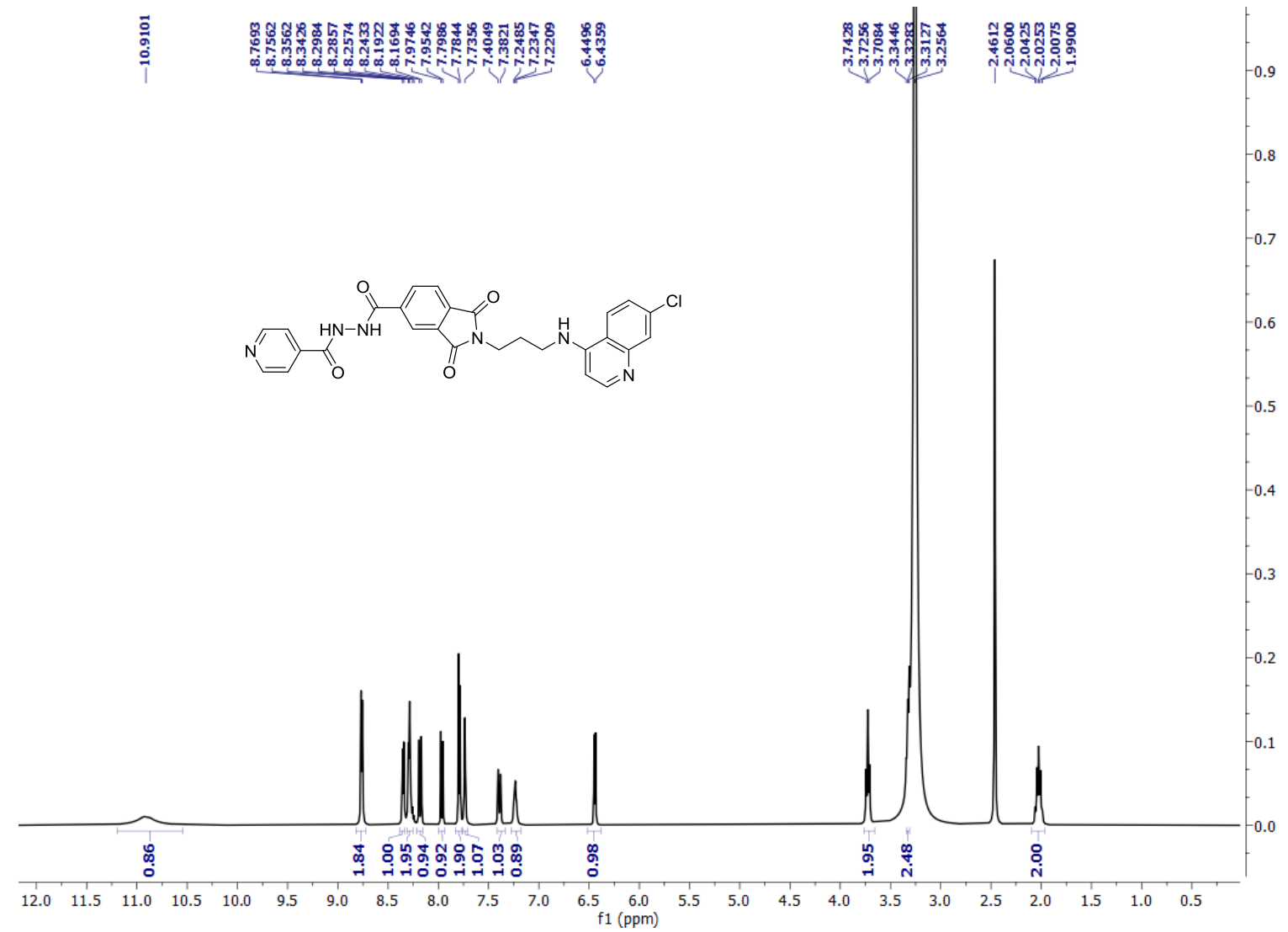


${ }^{13}$ C NMR of 2-(3-((7-chloroquinolin-4-yl)amino)propyl)-N'-isonicotinoyl-1,3dioxoisoindoline-5-carbohydrazide (6b):

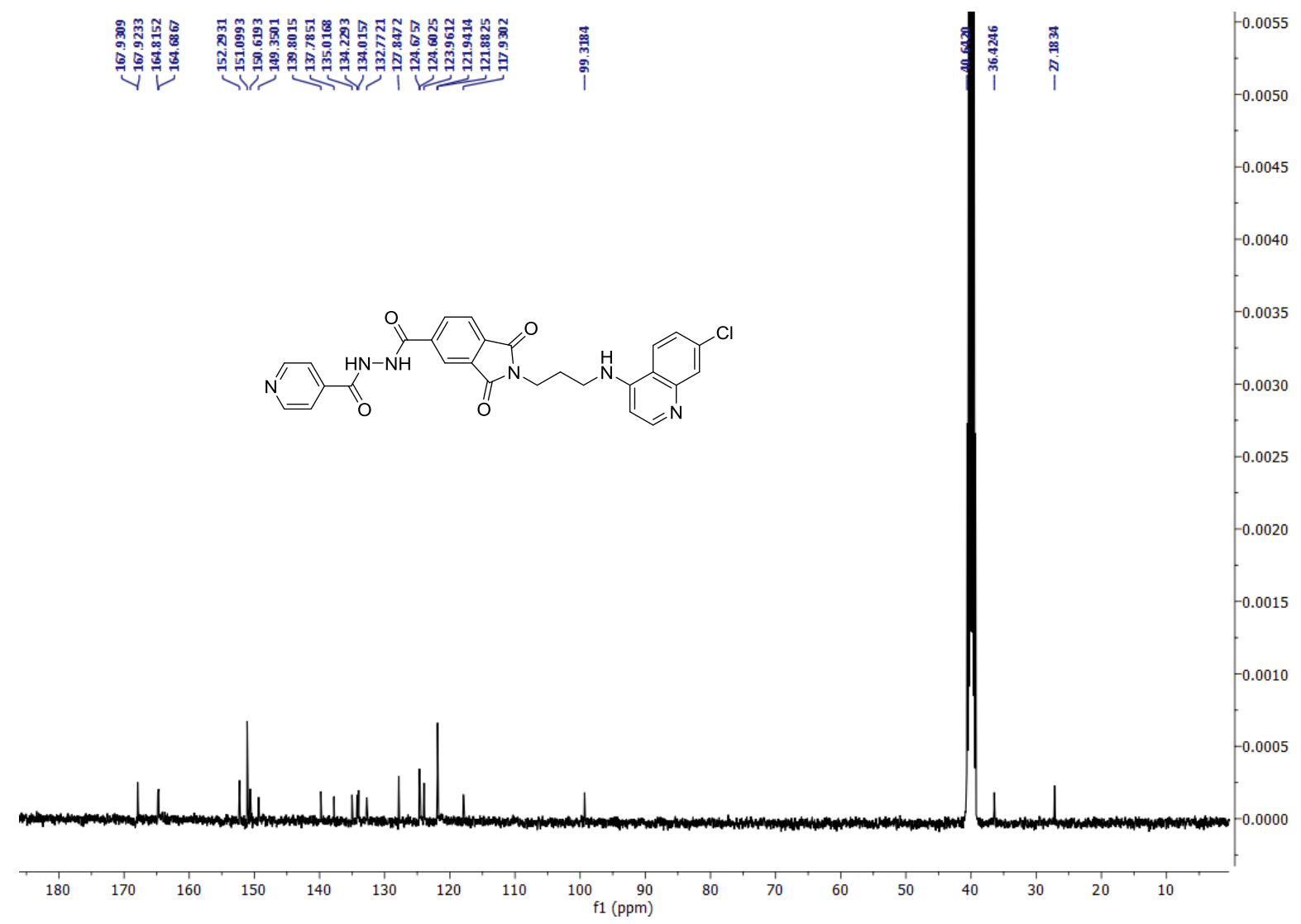

${ }^{1} \mathrm{H}$ NMR of 2-benzamido-1,3-dioxoisoindoline-5-carboxylic acid (7):

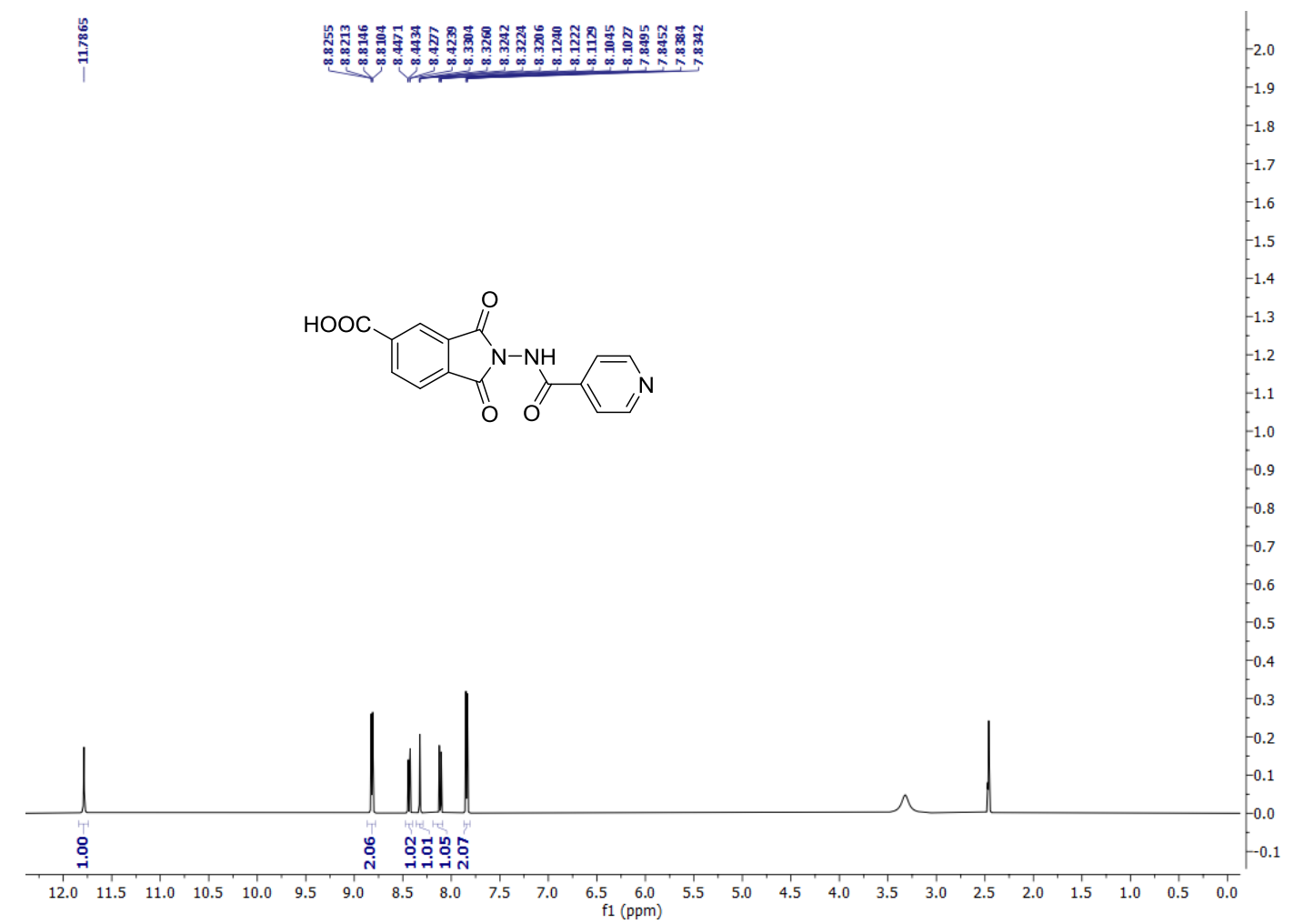


${ }^{1} \mathrm{H}$ NMR of N-(2-((7-chloroquinolin-4-yl)amino)ethyl)-2-(isonicotinamido)-1,3dioxoisoindoline-5-carboxamide (8a):

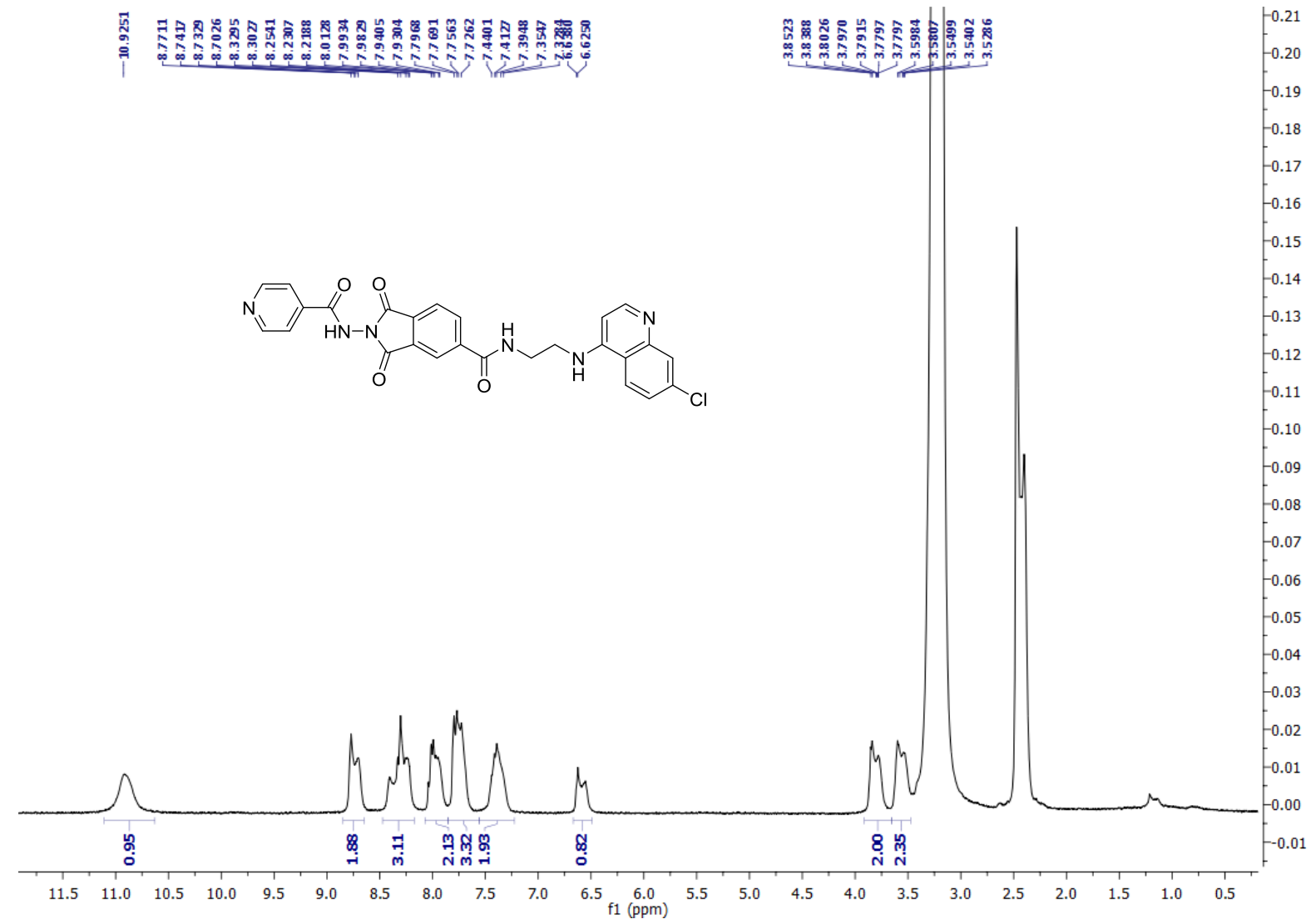

${ }^{13} \mathrm{C}$ NMR of $\mathrm{N}-(2-((7-c h l o r o q u i n o l i n-4-y l) a m i n o) e t h y l)-2-(i s o n i c o t i n a m i d o)-1,3-$ dioxoisoindoline-5-carboxamide (8a): 


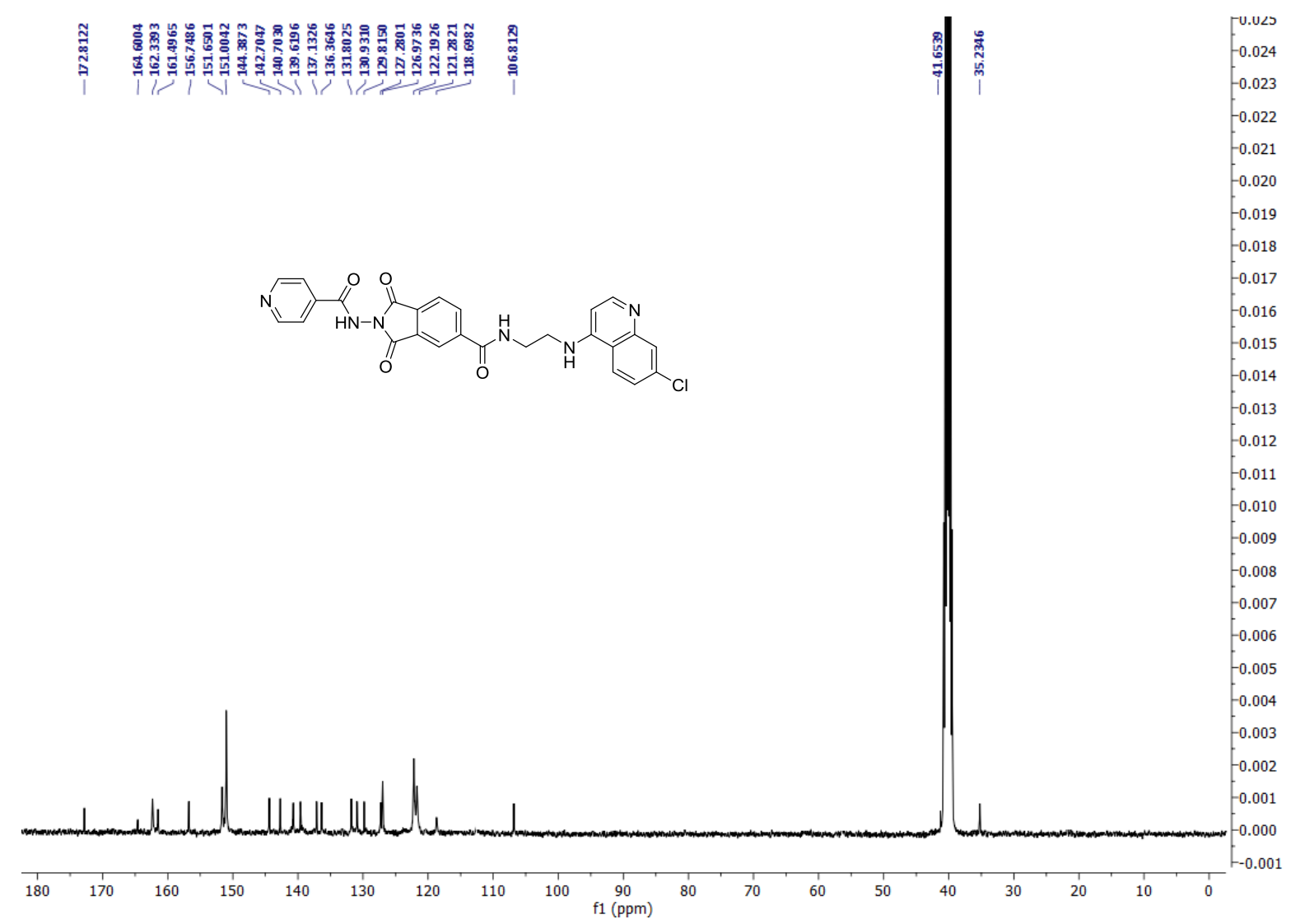

${ }^{1}$ H NMR of N-(5-fluoro-1,3-dioxoisoindolin-2-yl)benzamide (9):

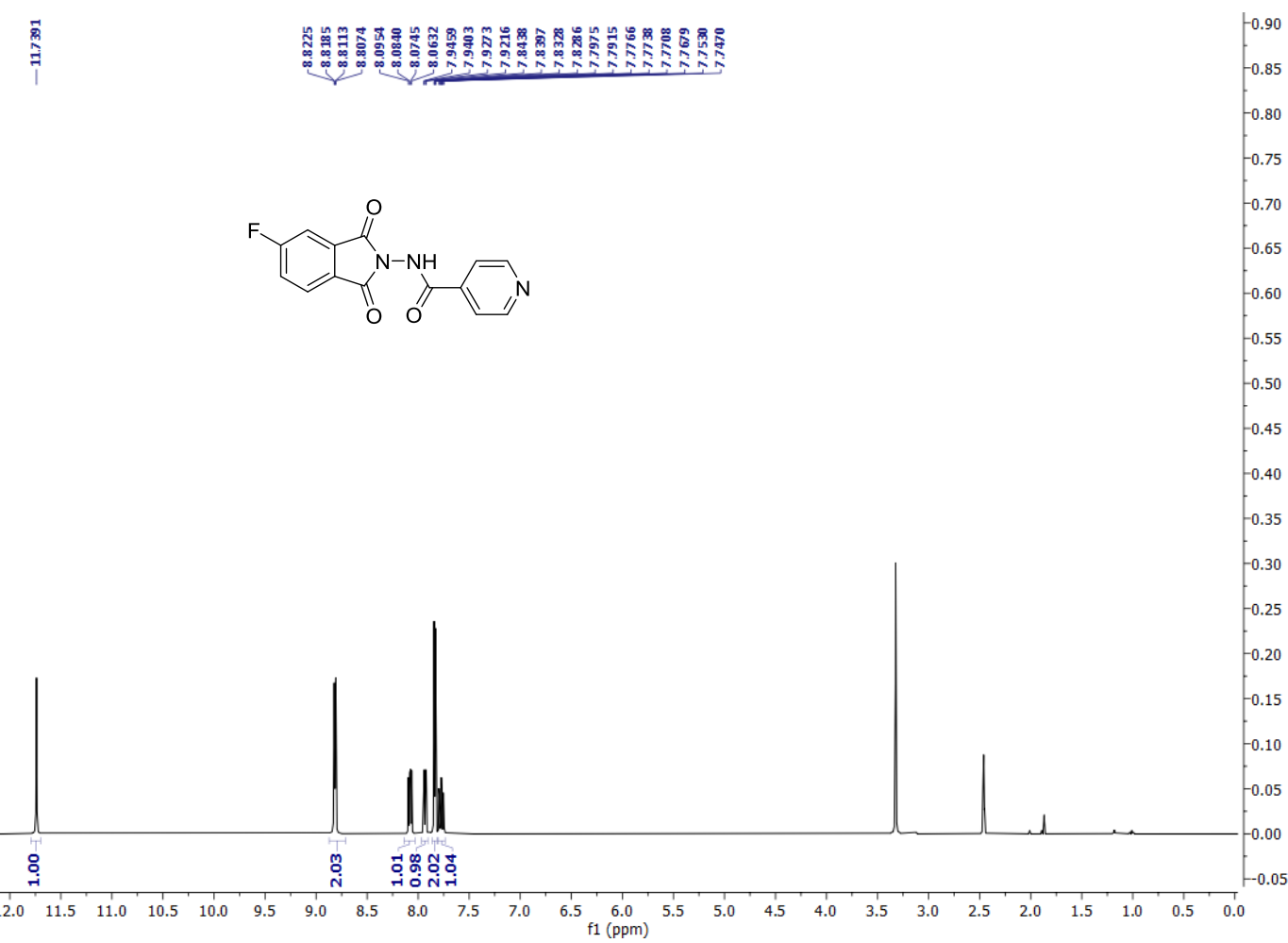

${ }^{13}$ C NMR of N-(5-fluoro-1,3-dioxoisoindolin-2-yl)benzamide (9): 


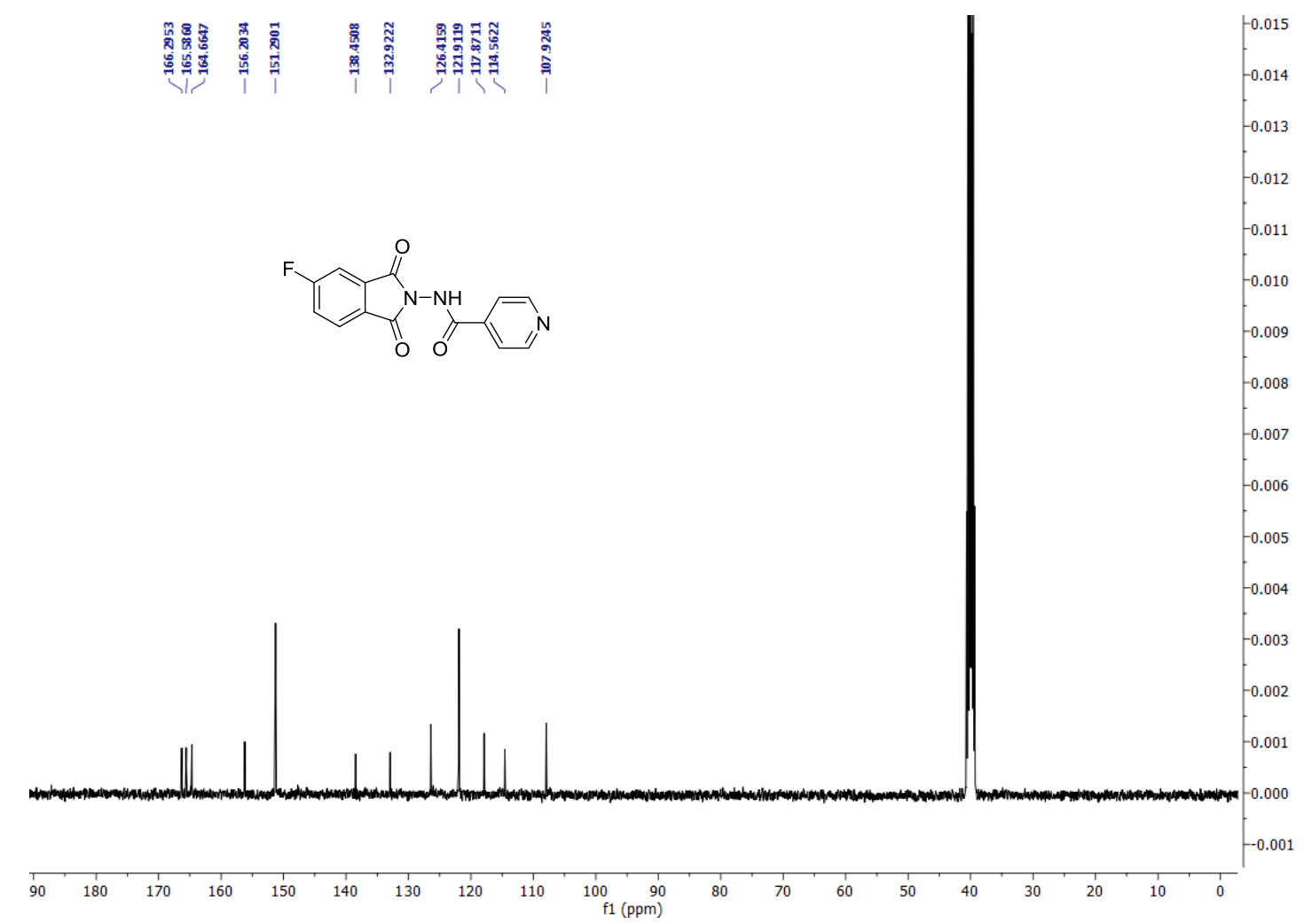

${ }^{1}$ H NMR of N-(5-(4-(7-chloroquinolin-4-yl)piperazin-1-yl)-1,3-dioxoisoindolin-2yl)isonicotinamide (11):

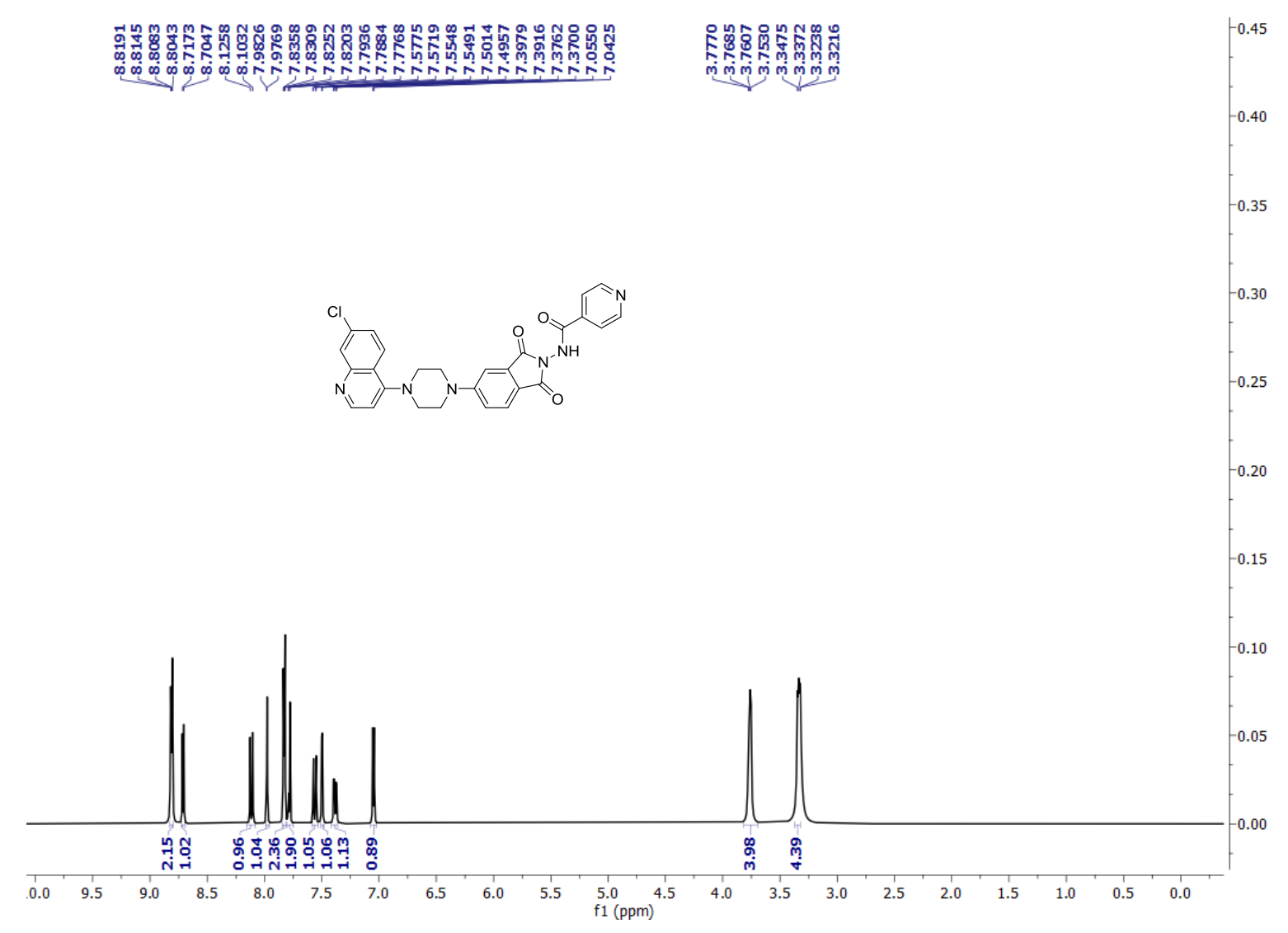


${ }^{13}$ C NMR of N-(5-(4-(7-chloroquinolin-4-yl)piperazin-1-yl)-1,3-dioxoisoindolin-2yl)isonicotinamide (11):

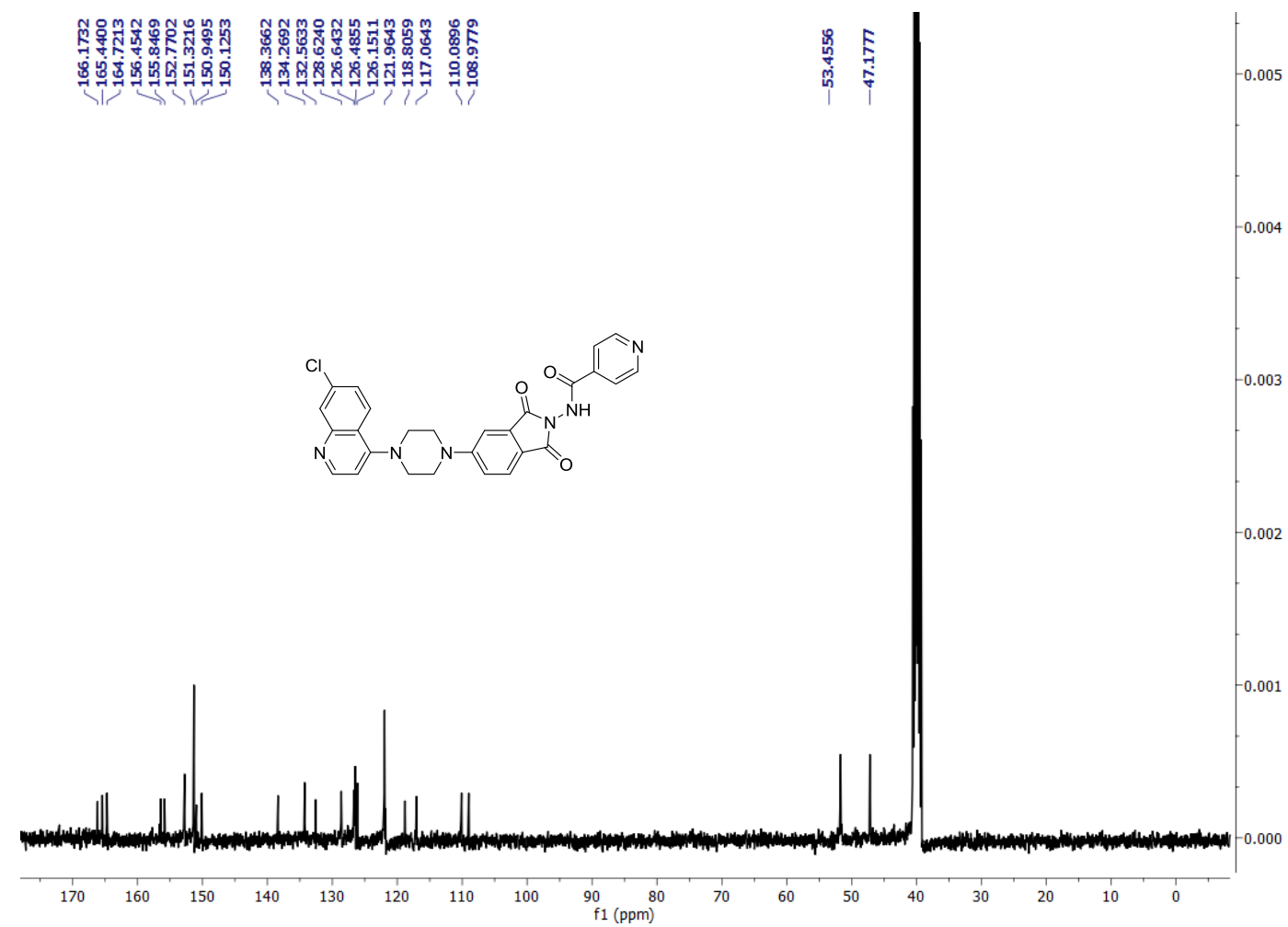

${ }^{1}$ H NMR of N'-(2-(1,3-dioxoisoindolin-2-yl)acetyl)isonicotinohydrazide (13a):

再

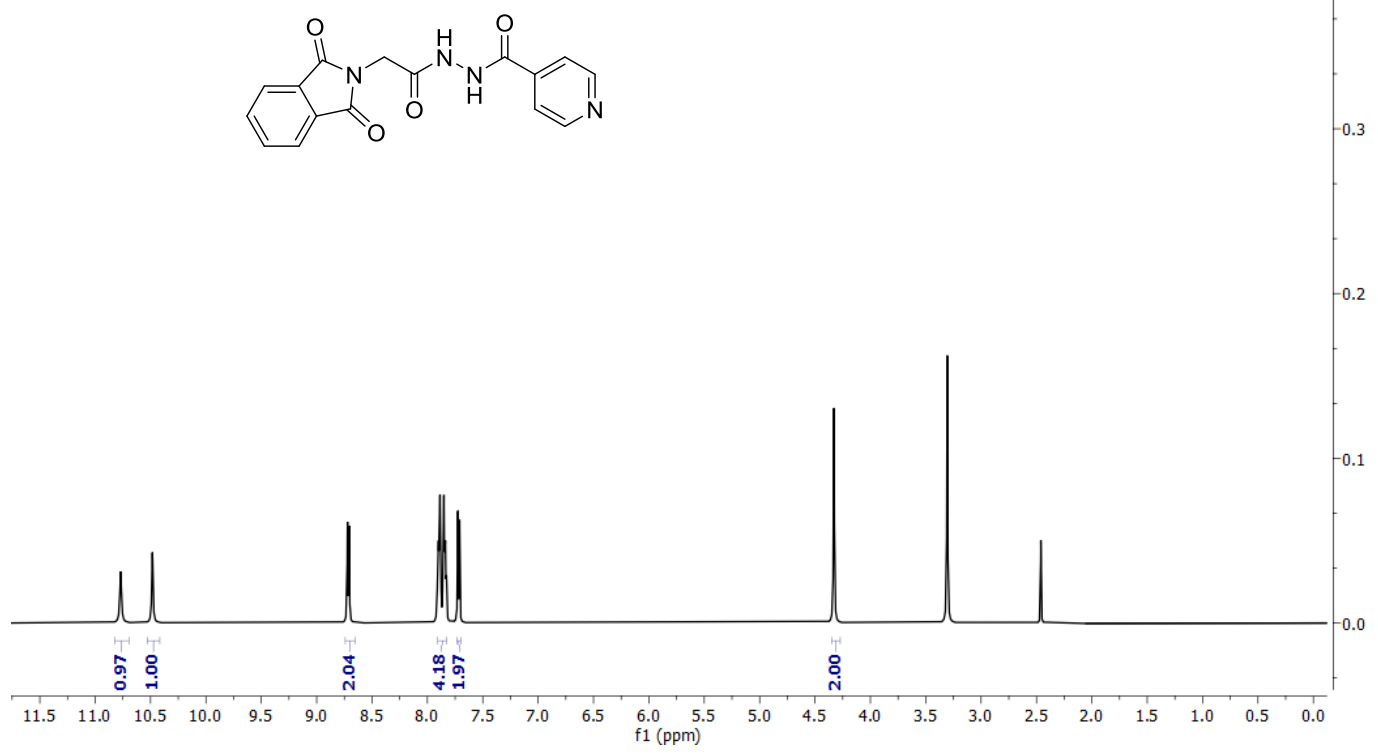

${ }^{13}$ C NMR of $N^{\prime}$-(2-(1,3-dioxoisoindolin-2-yl)acetyl)isonicotinohydrazide (13a): 


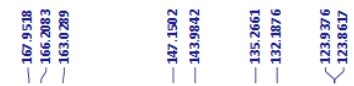
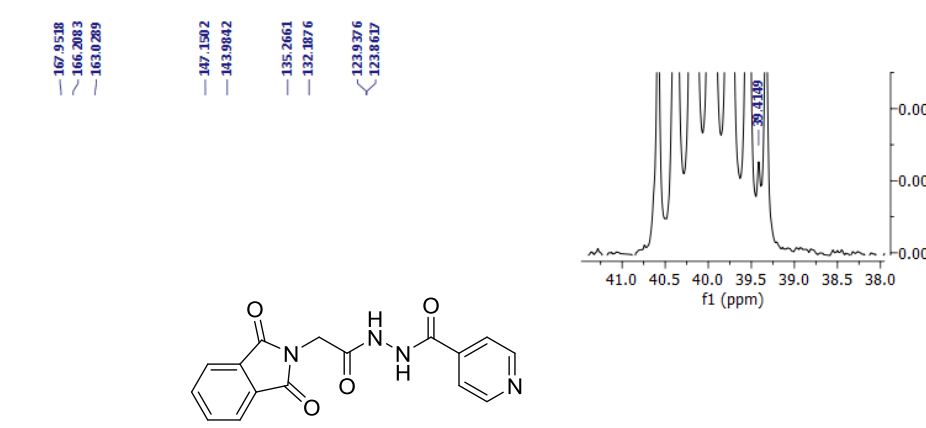

$\int_{0.01}^{-0.011}$

$\mathrm{f} 1(\mathrm{ppm})$
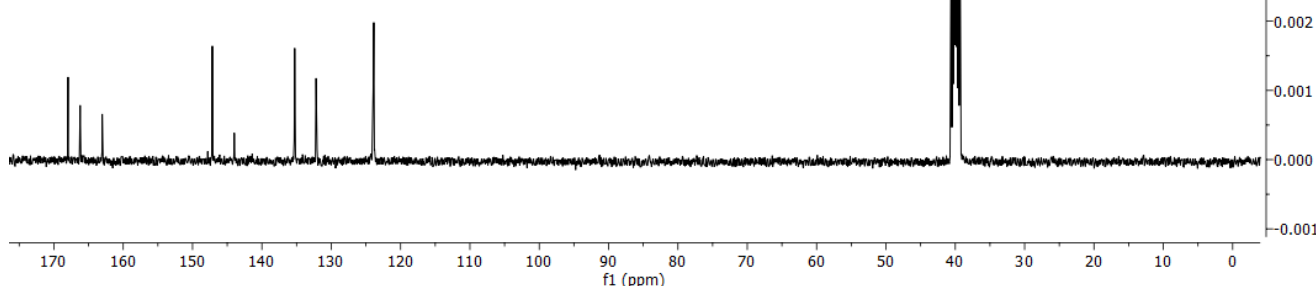


\section{${ }^{*}$ Declaration of Interest Statement}

\section{Declaration of interests}

$\bigotimes$ The authors declare that they have no known competing financial interests or personal relationships that could have appeared to influence the work reported in this paper. 